UNIVERSIDADE DE BRASÍLIA

PROGRAMA DE PÓS-GRADUAÇÃO EM GESTÃO PÚBLICA

FACULDADE DE PLANALTINA

\title{
AVALIAÇÃO DE IMPACTO DA FORMAÇÃO TÉCNICA PARA INSERÇÃO DOS ALUNOS EGRESSOS DO CAMPUS BRASÍLIA NO MUNDO DO TRABALHO
}

\author{
Elias Vieira de Oliveira
}

Dissertação de Mestrado em Gestão Pública

Planaltina (DF) 


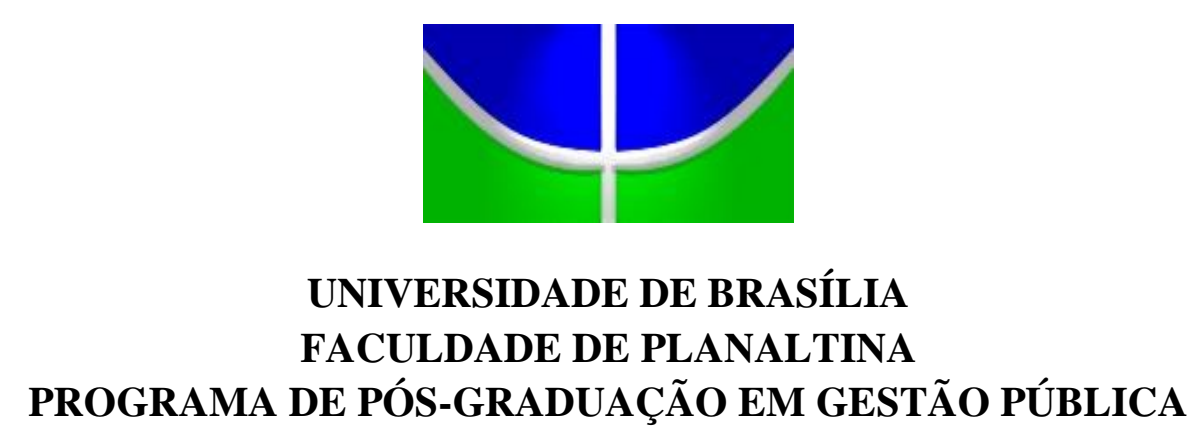

\section{AVALIAÇÃO DE IMPACTO DA FORMAÇÃO TÉCNICA PARA INSERÇÃO DOS ALUNOS EGRESSOS DO CAMPUS BRASÍLIA NO MUNDO DO TRABALHO}

\section{Elias Vieira de Oliveira}

Dissertação apresentada ao Programa de PósGraduação em Gestão Pública da Faculdade de Planaltina da Universidade de Brasília (UnB), como requisito para a obtenção do título de Mestrado Profissional em Gestão Pública sob a orientação do Professor Dr. Luiz Honorato da Silva Júnior. 
Oliveira, Elias Vieira de

OOL48a Avaliação de Impacto da Formação Técnica para Inserção dos Alunos Egressos do Campus Brasília no Mundo do Trabalho / Elias Vieira de Oliveira; orientador Luiz Honorato da Silva Júnior. -Brasilia, 2016.

$78 \mathrm{p}$.

Dissertação (Mestrado - Mestrado Profissional em Gestão Pública) - - Universidade de Brasília, 2016.

1. Avaliação de impacto. 2. Aluno egresso. 3. Mundo do trabalho. 4. Educação Profissional e Tecnológica. 5. Método de Diferença em Diferença. I. Silva Júnior, Luiz Honorato da, orient. II. Título. 


\title{
AVALIAÇÃO DE IMPACTO DA FORMAÇÃO TÉCNICA PARA INSERÇÃO DOS ALUNOS EGRESSOS DO CAMPUS BRASÍLIA NO MUNDO DO TRABALHO
}

\author{
Elias Vieira de Oliveira \\ Dissertação de Mestrado Profissional submetida ao Programa de Pós-Graduação em Gestão \\ Pública à Comissão Examinadora constituída por:
}

Professor Dr. Luiz Honorato da Silva Júnior (Presidente)

Programa de Pós-Graduação em Gestão Pública

Universidade de Brasília (UnB)

Professor Dr. André Nunes

Programa de Pós-Graduação em Gestão Pública

Universidade de Brasília (UnB)

Professora Dra. Patrícia Barcelos (membro externo)

Instituto Federal de Educação Ciência e Tecnologia do Rio Grande do Sul

Planaltina (DF), 28 de abril de 2016. 


\section{DEDICATÓRIA}

Dedico este trabalho a três grandes mulheres importantes em minha vida e que contribuíram com seus ensinamentos: minha mãe Elida Oliveira, que avessa às dificuldades da vida, em sua sabedoria, me ensinou o caminho do bem, à minha "irmãe", Elma Oliveira, pelas muitas horas de dedicação e orientação em meus estudos iniciais ensinando que este era o caminho e a minha filha Estela Carvalho de Oliveira, que me ensina constantemente o real significado do amor incondicional. 


\section{AGRADECIMENTOS}

Inicio agradecendo ao Professor Dr. Luiz Honorato da Silva Júnior, pelas horas de dedicação e orientação nesta pesquisa, penso que muitos dos ensinamentos irão reverberar ao longo desta trilha que inicia.

Agradeço aos demais professores da banca examinadora, Professores Dr. Alexandre Nascimento de Almeida, Dr. Remi Castioni e Dra. Patrícia Barcelos, por aceitar participar da banca e colaborar com suas experiências para a realização deste trabalho.

Quero agradecer aos muitos servidores do Instituto Federal de Brasília, Campus Brasília em especial ao colega José Henrique Marques Lopes, Coordenador do Registro Acadêmico pelo livre acesso as informações e dedicação de seu tempo, também à Professora Ms. Kátia Guimarães Sousa Palomo pelas dicas e companheirismo nas horas difíceis.

Também agradeço aos amigos José Alessandro da Silva e Nézio Fabiano Teles da Silva, por suas contribuições técnicas em suas áreas de atuação.

Obrigado Ludmila Pacheco pelas inúmeras palavras de conforto e encorajamento.

Um especial agradecimento, aos colegas e agora amigos de turma do Programa PPGP-FUP/2014 pelo companheirismo, participação e troca de ideias e boas energias. Este convívio me realimentou do ideal de uma sociedade mais fraterna e colaborativa, onde a lógica da construção e crescimento coletivo se oponha a concorrência e ao individualismo.

Por fim, Gracias a la vida por tudo que tem me dado:

Graças à vida que me deu tanto, Me deu o coração que agita seu marco Quando olho o fruto do cérebro humano Quando olho o bom tão longe do mal Quando olho o fundo de seus olhos claros 


\section{RESUMO}

$\mathrm{Na}$ avaliação de políticas públicas, diferentes instrumentos foram incorporados nos últimos anos como mecanismos gerenciais e de prestação de contas à sociedade. A avaliação de impacto é um destes instrumentos. No que diz respeito à Educação Profissional e Tecnológica Federal, enquanto política pública, significativos investimentos foram realizados após a publicação da Lei $\mathrm{n}^{\circ} 11.892$ de 29 de dezembro de 2008 que cria a Rede de Educação Profissional e Tecnológica, com a ampliação das unidades e da oferta educacional. Nesta pesquisa, a avaliação do desempenho desta política pública foi o aluno, sua inserção na vida laboral e no mundo do trabalho. Assim, esta pesquisa teve como objetivo geral realizar uma avaliação de impacto desta oferta educacional tendo a inserção no mundo do trabalho como referência de análise, por meio da utilização do método diferenças em diferenças, aplicado aos dados dos alunos egressos concluintes ou não dos cursos técnicos de Hospitalidade e Lazer, Serviços Públicos e Informática do Campus Brasília do Instituto Federal de Brasília, buscando compreender qual a contribuição desta formação para a inserção dos mesmos no mundo do trabalho. Os resultados encontrados, não conclusivos, reforçam a necessidade do aprofundamento de estudos estatísticos e de mecanismos e ferramentas para avaliação desta importante política pública, bem como a identificação de nossas variáveis explicativas, que possibilitem tornar o modelo ainda mais robusto.

Palavras-chave: Avaliação de impacto; Aluno egresso; Mundo do trabalho; Educação Profissional e Tecnológica; Método de Diferença em Diferença. 


\begin{abstract}
In the evaluation of public policies, various instruments have been incorporated in recent years as management mechanism and accountability to society. The impact assessment is one of these instruments. In regards of Federal Professional and Technological Education, as a public policy, significant investments were made after the publication of Law n. 11,892 of December, 29 of 2008 creating the Professional and Technological Education Network, with the expansion of the units and educational offer. In this research, the evaluation of the of this public policy performance was the student, their integration into working life and the world fo labor. Thus, this research aimed to carry out an impact assessment of this educational offer using the inclusion in the labor market as an analytical reference, by using the method difference in differences, applied to the data of the graduating and non-graduating students of the technical courses Hospitality \& Entertainment, Public Services and Computer Course of Brasília Campus from Brasília Federal Institute, seeking to understand the contribution of this training for the their insertion in the job market. The found results point to the need of deepening to the statistic studies and mechanisms and tools to the evaluation of this important public policy, as well as the identification of our variables explanations that makes possible make the model even more robust.
\end{abstract}

Keywords: Impact Evaluation; Graduating student; Student graduate; World of labor; Professional and Technological Education; Difference in Difference Method. 


\section{LISTA DE SIGLAS}

APL

CAPES

CEFETs

CODEPLAN

DF

IBGE

IDC

IFAC

IFB

IFS

MEC

MQO

OCDE

PIB

PNAD

PPGP

REDESIST

REPT

SEPLAN

SETEC

TIC

UNICEF
Arranjo Produtivo Local

Comissão de Aperfeiçoamento de Pessoas do Nível Superior

Centros Federais de Educação Tecnológica

Companhia de Planejamento do Distrito Federal

Distrito Federal

Instituto Brasileiro de Geografia e Estatística

International Data Corporation

Instituto Federal do Acre

Instituto Federal de Educação, Ciência e Tecnologia de Brasília

Institutos Federais de Educação, Ciência e Tecnologia

Ministério da Educação

Mínimos Quadrados Ordinários

Organização para a Cooperação e o Desenvolvimento Econômico

Produto Interno Bruto

Pesquisa Nacional por Amostra de Domicílios

Programa de Pós Graduação de Gestão Pública

Rede de Pesquisa em Sistemas Produtivos e Inovativos Locais

Rede Federal de Educação Profissional e Tecnológica

Secretaria de Planejamento do Distrito Federal

Secretaria de Educação Profissional e Tecnológica do Ministério da Educação

Tecnologia da Informação e da Comunicação

Fundo das Nações Unidas para a Infância 


\section{LISTA DE TABELAS}

Tabela 1 - Relação da situação de vínculo dos egressos com o mundo do trabalho.

Tabela 2 - Análise de regressão do efeito de tratamento em concluir os cursos de Eventos, Informática e Serviços Públicos, no Campus Brasília do IFB.

Tabela 3 - Distribuição da formação máxima dos pais por condição de egresso 55 


\section{LISTA DE QUADROS}

Quadro 1 - Distribuição dos alunos egressos, concluintes e evadidos dos cursos técnicos do Campus Brasília, por ano de ingresso

Quadro 2 - Distribuição do banco de dados, de alunos egressos que responderam ao questionário de informações

Quadro 3 - Percentual amostral da pesquisa em relação a população por grupo de concluintes e evadidos e ano. 33

Quadro 4 - Variáveis do Banco de Dados 33

Quadro 5 - Informações complementares e de percepção coletados no Questionário 35

Quadro 6 - Representação dos grupos utilizados na Pesquisa a partir do Método Diferenças em Diferenças (Diff-in-diff)

Quadro 7 - Perfil predominante do aluno egresso participante da pesquisa 46

Quadro 8 - Pesos atribuídos à formação dos pais na pesquisa 55 


\section{LISTA DE GRÁFICOS}

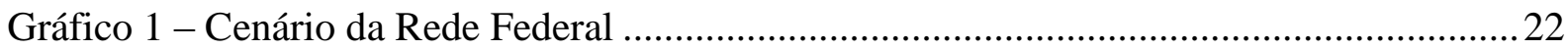

Gráfico 2 - Rendas médias dos grupos de tratamento e controle (antes e depois do período de

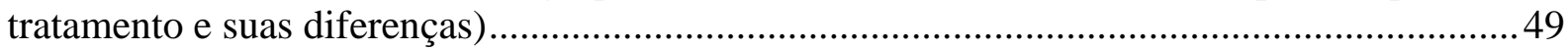




\section{SUMÁRIO}

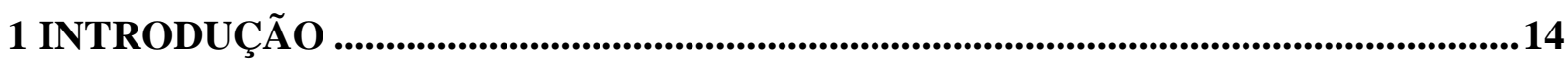

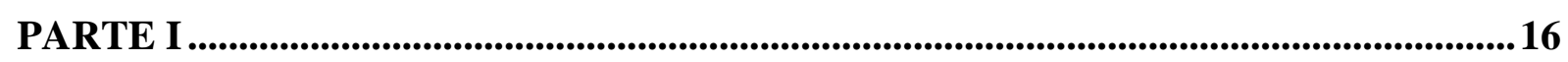

2 REFERENCIAL TEÓRICO ..................................................................................17

2.1 AVALIAÇÃO DE IMPACTO EM POLÍTICAS PÚBLICAS ............................................ 17

2.2 CONCEITO DO MUNDO DO TRABALHO PARA A EDUCAÇÃO PROFISSIONAL E

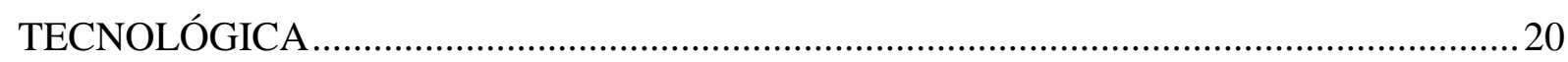

2.3 O INSTITUTO FEDERAL DE BRASÍLIA - CAMPUS BRASÍLIA NO CONTEXTO DA REDE DE EDUCAÇÃO PROFISSIONAL E TECNOLÓGICA ..............................................21

2.4 CONTEXTOS DAS ÁREAS DE ATUAÇÃO TÉCNICA DO CAMPUS BRASÍLIA: HOSPITALIDADE E LAZER, SERVIÇÕES PÚBLICOS E INFORMÁTICA NOS

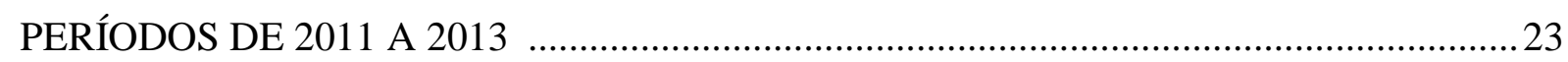

2.4.1 Contexto da área de Hospitalidade e Lazer .................................................................2 24

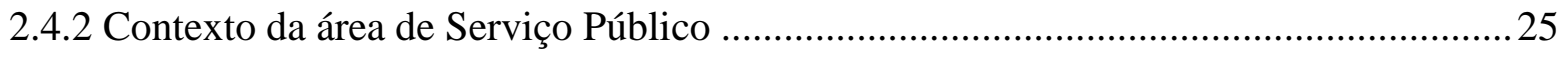

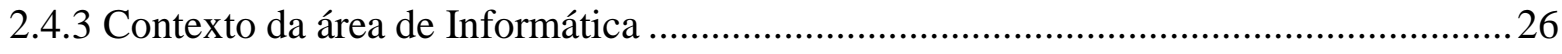

PARTE II ........................................................................................................................................27

3 REFERENCIAL METODOLÓGICO ......................................................................28

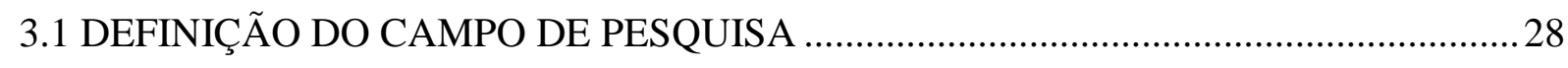

3.1.1 Identificação dos Grupos de Tratados e Controle - Estratégica Empírica......................30

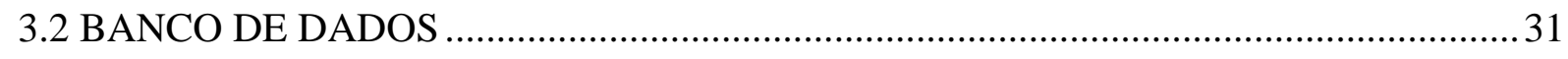

3.2.1 Levantamento do banco de dados ..............................................................................

3.2.2 Composição das informações do banco de dados ............................................................ 33 
3.3 MÉTODOS UTILIZADOS EM AVALIAÇÃO DE IMPACTO - DIFERENÇAS EM

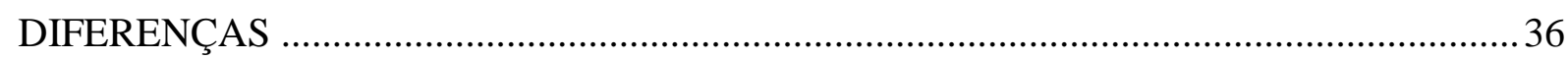

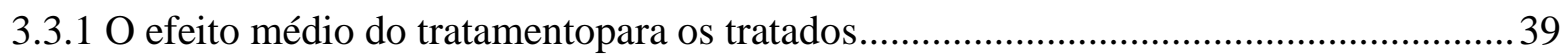

3.3.2 Estimação por dados em painel com efeito fixo: dois períodos .................................. 40

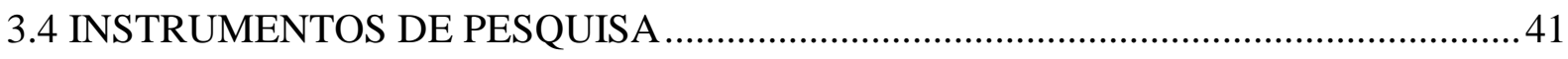

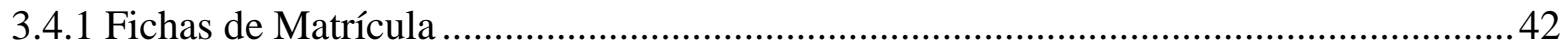

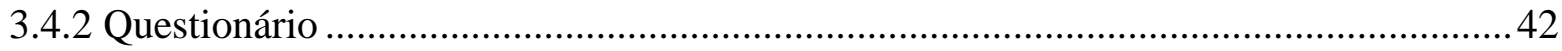

3.5 LIMITAÇÕESENCONTRADAS PARA A REALIZAÇÃO DA PESQUISA ..................43

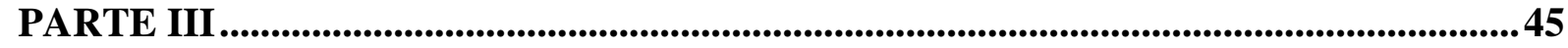

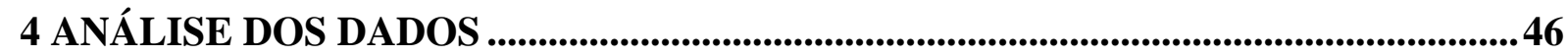

4.1 PERFIL PREDOMINANTE DO ALUNO EGRESSO DO INSTITUTO FEDERAL DE

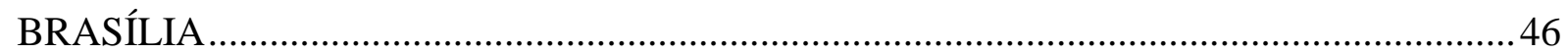

4.2 RELAÇÃO DOS EGRESSOS COM O MUNDO DO TRABALHO............................... 47

4.3 ANÁLISE DOS IMPACTOS DA FORMAÇÃO, A PARTIR DAS INFORMAÇÕES

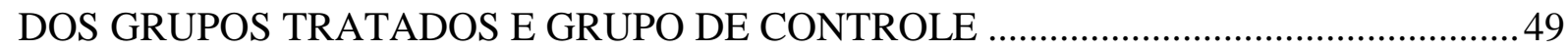

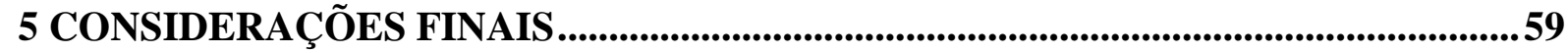

REFERÊNCIAS BIBLIOGRÁFICAS ............................................................................6 63

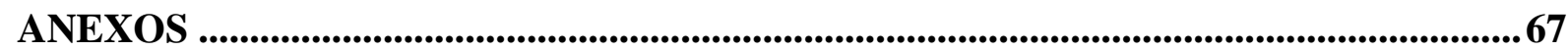




\section{INTRODUÇÃO}

No início de 2008, face às comemorações do Centenário das Instituições de Educação Profissional e Tecnológica Federais, o Ministério da Educação (MEC) por meio da Secretaria de Educação Profissional e Tecnológica (SETEC), publicou um instrumento de avaliação denominado Pesquisa Nacional de Egressos dos Cursos Técnicos da Rede Federal de Educação Profissional e Tecnológica (BRASIL, 2008). Este estudo teve como referência um universo de 2.650 alunos egressos do período de 2003 a 2007, de todas as regiões do país e considerava em seu escopo, além da empregabilidade destes, a continuidade de estudos e adequação da formação profissional recebida. Até o momento, parece ser o único instrumento de avaliação realizada pelo MEC, da política de Educação Profissional e Tecnológica da Rede Pública Federal, realizado como elemento de análise, tomando como referencial o aluno egresso.

Após a edição da pesquisa supracitada, a Rede Federal de Educação Profissional e Tecnológica viveu um forte crescimento em sua estrutura física e de oferta educacional, conforme evidenciado nos Planos de Expansão do Governo Federal (BRASIL, 2007). Em números, a quantidade de unidades da Rede saiu de 140 unidades em 2002 para 562 unidades em 2014, ou seja, um aumento de 400\% em uma década (BRASIL, 2015).

A Pesquisa Nacional de Egressos (BRASIL, 2008) foi um importante referencial para execução da pesquisa empreendida. No entanto, cabe destacar que, para além de estar em um cenário diferenciado da gestão da Rede Federal de Educação Profissional e Tecnológica (REPT), pois foi aplicada antes da Lei de reestruturação e criação dos Institutos Federais, ela apresenta uma característica de análise ampliada, portanto macro, da realidade dos alunos egressos.

É evidente que a expansão das instituições e ofertas de vagas, contribuiu significativamente para a democratização do acesso a esta modalidade de Educação, no entanto abre a necessidade de mais pesquisas para avaliar a efetividade desta política pública e sua relação com o gasto público.

Para se refletir sobre a contribuição desta política pública, o Instituto Federal de Brasília (IFB) deve perseguir seu objeto efetivo que é para além dos aspectos políticospedagógico, que dizem respeito à percepção destes em relação aos conhecimentos adquiridos 
e sua capacidade crítica frente aos processos laborais, mas também proporcionar elementos que possibilitem condições de maiores chances de empregabilidade, aumento da renda e êxito no mundo do trabalho.

Atualmente dentro da Rede de Educação Profissional e Tecnológica, algumas iniciativas isoladas têm se apresentado no sentido de responder ao questionamento em relação à contribuição e qualificação da oferta educacional dos Institutos Federais para a empregabilidade e aumento de renda de seus alunos. Uma destas iniciativas, no Campus Brasília do IFB, foi a criação do grupo de pesquisa denominado Observatório do Mundo do Trabalho, que entre suas linhas de atuação está a criação de mecanismos de monitoramento e avaliação da empregabilidade dos alunos egressos, no entanto, as iniciativas a este respeito ainda são incipientes.

Considerando a limitação de existência de instrumentos de avaliação permanentes e periódicos na Rede Federal, com enfoque no objeto resultado de sua atuação, ou seja, o aluno egresso, esta pesquisa contribui para a reflexão sobre o tema, que tem por objetivo geral a avaliação de impacto desta oferta educacional tendo a inserção no mundo do trabalho como referência de análise, por meio da utilização do método diferenças em diferenças, aplicado aos dados dos alunos egressos concluintes ou não dos cursos técnicos de Hospitalidade e Lazer, Serviços Públicos e Informática do Campus Brasília do Instituto Federal de Brasília, a fim de compreender o impacto desta formação na inserção destes e, por consequência, no aumento de renda.

São também objetivos específicos desta pesquisa:

a) Estimar os impactos na renda, a partir da análise de informações entre os grupos de tratados e grupo de controle.

b) Identificar o perfil do aluno egresso do Instituto Federal de Brasília, a partir do instrumento de pesquisa.

Neste sentido, esta pesquisa persegue a ideia de orientar a reflexão e a prática sobre indicadores de avaliação para a política de Educação Profissional e Tecnológica, com a certeza de que é necessário avançar na construção de mecanismos de avaliação e monitoramento de políticas públicas. 
PARTE I 


\section{REFERENCIAL TEÓRICO}

\subsection{AVALIAÇÃO DE IMPACTO EM POLÍTICAS PÚBLICAS}

No Brasil, em especial na área educacional, ainda são incipientes os estudos de avaliação de impacto, ao consultarmos os principais sites de produção acadêmica, encontramos poucas referências a este processo avaliativo. Os estudos contidos nestes depositórios em sua maioria fazem referências às avaliações acadêmicas ou de estrutura da organização ofertante, pouco se evidencia sobre a análise dos impactos da oferta educacional tendo a inserção no mundo do trabalho como referência de análise.

Para Menezes Filho (2012), a pouca expressividade de avaliações de impacto nas políticas sociais é um reflexo da pouca identificação de economistas e cientistas sociais com programas e estudos na área social. No entanto, tem se identificado nas últimas décadas preocupação com este modelo de avaliação, considerando a escassez de recursos na área social e por consequência a necessidade de melhor alocação, portanto ter a dimensão do efetivo resultado dessas ações.

Neste sentido, a avaliação de impacto, como um dos meios de avaliação econômica pode aferir o efeito de um programa sobre os seus usuários e mais, a amplitude desta ação.

Menezes Filho (2012), afirma ainda que para o sucesso deste processo é necessário à existência de alguns elementos:

a) A identificação clara dos objetivos que o programa intenciona atingir, traduzidos na identificação de indicadores objetivos e mensuráveis, que possam ser utilizados para aferir o sucesso do programa.

b) A existência de um grupo de controle, que possa funcionar como contra factual ao grupo de usuários da política ou programa.

c) A possibilidade de comparação e relação entre os benefícios incorporados pela ação e seus custos. 
Partindo destas considerações iniciais, este projeto propõe a partir da avaliação de impacto dimensionar se os resultados esperados com a oferta dos cursos técnicos no Campus Brasília, estão sendo efetivamente alcançados, para além do ponto de vista acadêmico, mas também social e econômico, tomando como referência alguns elementos contidos na política pública de Educação Profissional e tecnológica, traduzida na definição e análise socioeconômica de seus alunos egressos, em especial no que diz respeito a sua inserção no mundo do trabalho.

Considerando que o objeto de análise deste estudo é uma política pública o conceito de avaliação será referendado por dois órgãos internacionais que atuam na reflexão sobre desenvolvimento humano e econômico, o Fundo das Nações Unidas para a Infância (UNICEF) e a Organização para a Cooperação e o Desenvolvimento Econômico (OCDE).

Para a UNICEF (1990), avaliação é o exame sistemático e objetivo de um projeto ou programa, finalizado ou em curso, que contemple o seu desempenho, implementação e resultados, com vistas à determinação de sua eficiência, efetividade, impacto, sustentabilidade e a relevância de seus objetivos. O propósito da avaliação é guiar os tomadores de decisão, orientando-os quanto à continuidade, necessidade de correções ou mesmo suspensão de uma determinada política ou programa.

Já a OCDE (2015) define em seu glossário de termos para avaliação e desempenho as mesmas ideias, no entanto adiciona que a mesma deve prover informações com crédito e utilidade, permitindo o aprendizado no processo de tomada de decisões. Acrescenta ainda que se constitui na determinação de valor ou significância de uma atividade, política ou programa. É um julgamento, tão sistemático e objetivo quanto possível, a respeito das intervenções governamentais.

Cohen e Franco (2008) em seu estudo Avaliação de Projetos Sociais apresenta o conceito de impacto como sendo o resultado do programa que pode ser atribuído exclusivamente às suas ações, após a eliminação dos efeitos externos. É o resultado líquido do programa e indica se o projeto tem efeitos, positivos, no ambiente externo em que interveio em termos técnicos, econômicos, socioculturais, institucionais e ambientais.

Com base nestes conceitos, concluímos que avaliação de impacto pode ser definida como o resultado do exame sistemático e objetivo de um projeto ou programa, que pode ser atribuído às suas ações, sobre determinação de diferentes conceitos, cujo objetivo é fazer correções ou mesmo indicar a suspensão do mesmo, com base nos efeitos ou resultados produzidos no ambiente externo em que atua. 
Quanto a sua finalidade, Frey (2002) aponta que a avaliação é imprescindível para o desenvolvimento e a adaptação contínua das formas e dos instrumentos de ação pública, denominado por ele como a como fase de aprendizagem política. $\mathrm{O}$ autor defende ainda que a avaliação é um dos elementos de garantia e efetividade da ação governamental, esta pensada como mecanismo de mensuração do desempenho desta ação. Nas políticas sociais em especial, a avaliação apresenta-se com um dos requisitos fundamentais no acompanhamento do desempenho e como mecanismo de controle dos recursos aplicados.

Para Arretche (2001), a avaliação serve como um verdadeiro instrumento democrático de controle sobre a ação social, sendo possíveis as discussões públicas onde os cidadãos têm pleno acesso às informações, à metodologia empregada e aos resultados alcançados.

Vencida a compreensão sobre o conceito e a finalidade, Faria (2005) classifica a avaliação em relação a seu de uso:

- Instrumental - depende não apenas da qualidade da avaliação, mas também da adequada divulgação de seus resultados, sua inteligibilidade e da factibilidade das recomendações propostas;

- Conceitual - as descobertas da avaliação podem alterar a maneira como esses técnicos entendem a natureza, o modo de operação e o impacto do programa que estão implementando. Nenhuma decisão ou ação é esperada, pelo menos não imediatamente;

- Instrumento de persuasão - quando a avaliação é utilizada para mobilizar o apoio para a posição que os tomadores de decisão já têm sobre as mudanças necessárias na política ou programa;

- "Esclarecimento" - "[...] acarreta, pela via do acúmulo de conhecimento oriundo de diversas avaliações, impacto sobre as redes de profissionais, sobre os formadores de opinião e sobre as advocacy coalitions, bem como alterações nas crenças e na forma de ação das instituições" (FARIA, 2005, p.103), orientando a agenda governamental. 
Ainda em relação ao uso, Faria (2005) define como usuários ou público-alvo da ação de avaliação: gerentes de programas similares e/ou de diferentes níveis governamentais; agentes do governo e representantes de fundações, interessados em conhecer projetos bemsucedidos que mereçam financiamento ou preocupados em aprimorar os programas dos quais são responsáveis; membros do Legislativo interessados na melhoria de programas existentes ou na elaboração de novas propostas; cientistas sociais e outros avaliadores que buscam aprender com as descobertas e com as metodologias empregadas.

No entanto, o interesse final das avaliações de impacto deve ser a sociedade em geral e, principalmente, o público usuário destes serviços. Construir mecanismos que garantam uma ampla divulgação destas avaliações, pode ser também, um importante mecanismo de controle social.

\subsection{CONCEITO DE MUNDO DO TRABALHO PARA A EDUCAÇÃO PROFISSIONAL E TECNOLÓGICA}

O atual cenário de complexidades econômicas e sociais tem apresentado ao Ensino Técnico Profissionalizante, um profundo debate de caráter ideológico e institucional a esta modalidade de oferta educacional, no sentido de sua definição e públicos.

Direcionada a formação de mão de obra especializada, esta mantém uma relação direta com o trabalho, tendo inicialmente uma inserção nas classes sociais menos favorecidas econômica e prioritariamente na classe trabalhadora. Outra característica desta formação é o desenvolvimento de habilidades laborais, definidas pelas necessidades do mercado de trabalho.

No entanto, novas definições tem se apresentado à relação Educação Profissional e mercado de trabalho, denotando a necessidade de aprofundamento sobre a categoria "formação" como sendo o processo de desenvolvimento humano que visa atuar sobre os espaços de produção e de sociabilidade.

O crescente avanço tecnológico e a escassez de recursos produtivos e de mão de obra qualificada, entre outros fatores determinam uma necessidade acirrada de competitividade entre as organizações, que por consequência reflete nos indivíduos, que necessitam o ingresso e o a permanência neste mercado de trabalho. 
Neste contexto, é papel do Estado apresentar possibilidades de soluções para a profissionalização da população. Assim, cabe à escola a competência de lidar com as questões referentes às relações de trabalho através dos atores que agem e interagem com o mercado de trabalho.

Ciavatta (2008) defende que a Educação Profissional deve ser vista como uma resposta estratégica aos problemas postos pela globalização econômica, pela reestruturação produtiva, pela busca da qualidade e da competitividade e pelas transformações do mundo do trabalho decorrentes das novas tecnologias, fatores estes que produzem o processo de desemprego estrutural.

Ainda a respeito desta estratégia de resposta e o papel da escola frente a estes desafios, segundo Frigotto e Ciavatta (2004) esta não deve se atrelar ao produtivismo do mercado de trabalho, mas sim em uma concepção de formação do homem para a cidadania, produzindo assim o conceito de formação para o mundo do trabalho.

Esta formação para o mundo do trabalho direciona a Educação Profissional para uma qualificação mais abrangente, no entanto focada na capacidade crítica frente aos processos produtivos, ou seja, o mercado exige menos o apertador de parafusos dos modelos de Ford e Taylor, e busca um profissional com competências técnicas próprias da especialidade profissional construída em bases críticas, de responsabilidade social, capacidade de reação e interação com diferentes grupos, indivíduos e realidades (FRIGOTTO; CIAVATTA, 2004).

Assim a Educação Profissional deve apoiar-se em diferentes elementos constantemente sujeitos a construção e desenvolvimento do caráter cognitivo crítico e que são determinantes para a compreensão, a interpretação e a adaptação às circunstâncias institucionais da sociedade e das relações do trabalho.

\subsection{O INTITUTO FEDERAL DE BRASILIA - CAMPUS BRASÍLIA NO CONTEXTO DA REDE FEDERAL DE EDUCAÇÃO PROFISSIONAL E TECNOLÓGICA}

Em dezembro de 2008, após tramitar por cerca de dois anos no Congresso Nacional, o Governo Federal sanciona Lei ${ }^{\circ}$ 11.892/2008, que institui a Rede Federal de Educação Profissional, Científica e Tecnológica e cria os Institutos Federais de Educação, 
Ciência e Tecnologia (BRASIL, 2008). Com a aprovação desta lei, a Rede Federal passa a contar com 562 unidades, como se verifica no gráfico abaixo.

\section{Gráfico 1 - Cenário da Rede Federal}

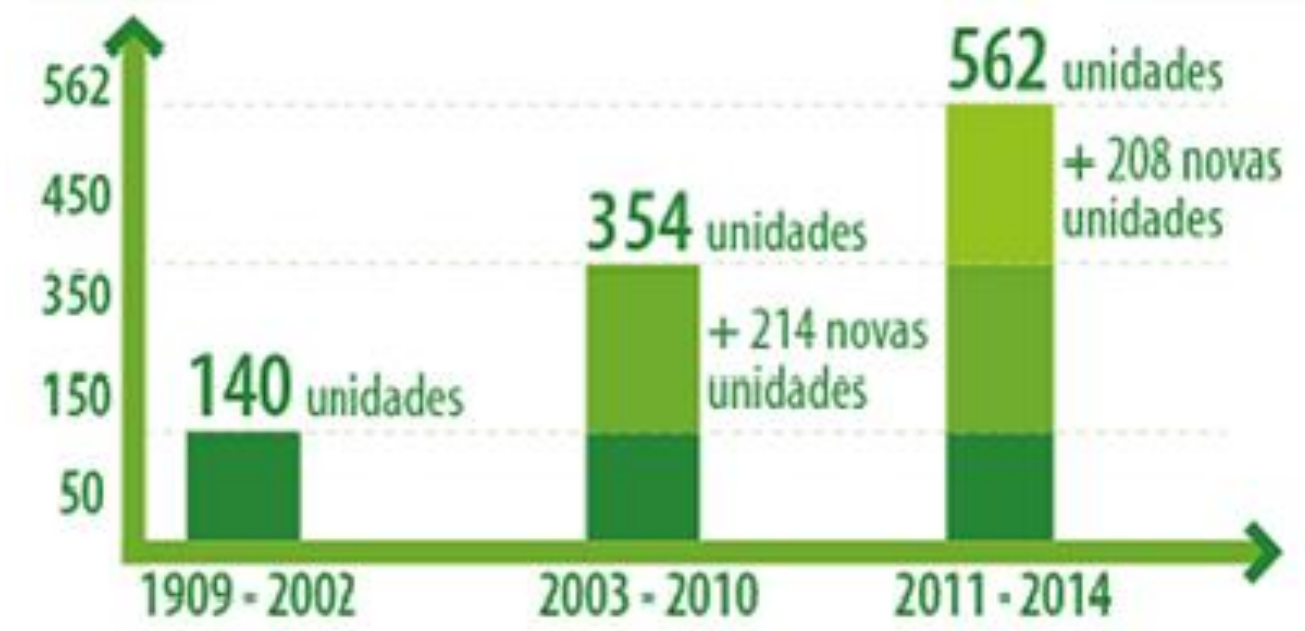

Fonte: http://institutofederal.mec.gov.br/?Itemid=2\&id=52\&option=com_content\&view=article

Esta lei reorganiza também a gestão da Educação Profissional e Tecnológica Federal, através da fusão de várias autarquias: Escolas Técnicas Federais, das Escolas Agrotécnicas e dos Centros Federais de Educação Tecnológica (CEFETs) em 38 autarquias denominadas Institutos Federais de Educação, Ciência e Tecnologia (IFS). Estas instituições com característica multicampi e com perfil de oferta de educação superior, básica e profissional de forma pluricurriculares.

No Distrito Federal, foi criado o Instituto Federal de Brasília (IFB) por meio da transformação da Escola Técnica de Brasília. De imediato essa autarquia, além de sua unidade inicial em Planaltina, recebeu autorização de funcionamento de mais quatro campi assim definidos: Brasília, Gama, Samambaia e Taguatinga.

Para a definição das áreas de conhecimento de cada um destes campi, além de consultas públicas e aplicação de metodologias de avaliação, foram utilizados mecanismos de avaliação dos Arranjos Produtivos Locais (APL), seguindo assim, orientação defendida pelo Governo Federal. Estes APLs consideram além das características econômicas da região em que estão inseridos, também elementos de avaliação de empregabilidade da população (SANTOS, 2007). 
A partir da análise deste conjunto de mecanismos de definição, coube ao Campus Brasília do IFB a atuação em quatro áreas: Gestão Pública, Informática, Lazer e Hospitalidade e Dança. Para estas áreas, além da formação técnica e da formação inicial e continuada, há também a oferta de graduações tecnológicas, licenciaturas e especializações.

\subsection{CONTEXTO DAS ÁREAS DE ATUAÇÃO TÉCNICA DO CAMPUS BRASILIA: HOSPITALIDADE E LAZER, SERVIÇOS PÚBLICOS E INFORMÁTICA NOS PERÍODOS DE 2011 A 2013}

Sanches (2008) afirma que o primeiro autor a trabalhar as questões de aglomerações produtivas locais foi Marshall, em 1890, através do conceito de distritos industriais. Estes estudos apontam para uma configuração defendida por Marshall baseada em princípios de eficiência econômica, no sentido de produção de riqueza em médio e longo prazo, incluindo ainda a questão da reprodução das condições econômicas que permitam manter o processo produtivo.

Embora houvesse estudos em longo prazo, somente na década de 1990, pesquisadores e gestores de políticas públicas no Brasil passaram a pesquisar e aprofundar o delineamento de políticas públicas destinadas às aglomerações produtivas, buscando a definição de uma nomenclatura que defina estes espaços, segundo Santos (2007) neste período passaram a associar ao conceito o princípio da competitividade, através da aproximação geográfica das empresas.

Em 1997, surge no Brasil a Rede de Pesquisa em Sistemas Produtivos Locais (REDESIST), sediada no Instituto de Economia da Universidade Federal do Rio de Janeiro. Desta associação de pesquisadores resulta o conceito de arranjo produtivo local, APL, definido como aglomerações territoriais de agentes econômicos, políticos e sociais com foco em um conjunto específico de atividades econômicas.

O termo Arranjo Produtivo Local (APL) foi rapidamente disseminado na esfera de ensino e pesquisa e de política, tornando-se um termo capaz de abrigar uma ampla diversidade do fenômeno, e se constituindo em instrumento de política econômica.

Conforme a definição proposta pela RedeSist: 


\begin{abstract}
Arranjos Produtivos Locais são aglomerações territoriais de agentes econômicos, políticos e sociais - com foco em um conjunto específico de atividades econômicas - que apresentam vínculos mesmo que incipientes. Geralmente envolvem a participação e a interação de empresas - que podem ser desde produtoras de bens e serviços finais até fornecedoras de insumos e equipamentos, prestadoras de consultoria e serviços, comercializadoras, clientes, entre outros - e suas variadas formas de representação e associação. Incluem também diversas outras instituições públicas e privadas voltadas para: formação e capacitação de recursos humanos, como escolas técnicas e universidades; pesquisa, desenvolvimento e engenharia; política, promoção e financiamento (LASTRES; CASSIOLATO, 2003, p. 3).
\end{abstract}

Buarque (2002) em Construindo um Desenvolvimento Local Sustentável defende o conceito de desenvolvimento local como um processo de mudança, que leva ao dinamismo econômico e à melhoria da qualidade de vida da população em pequenas unidades territoriais e agrupamentos humanos.

Defende ainda o autor, que cada local deve a partir de suas características e potencialidades, procurar espaços de competitividade, neste sentido priorizar esforços, entre eles, os recursos humanos oferecendo a sua população educação e formação profissional (BUARQUE, 2002).

Portando, tanto a definição de Arranjo Produtivo Local (APL) apresentada pela REDESIST, defendida por Lastres e Cassiolato (2003) quanto a definição de Buarque (2002), incorporam os recursos humanos e a formação profissional como elementos estruturantes para o sucesso e desenvolvimento dos arranjos produtivos locais.

Na sequência, apresentaremos um resumo dos APLs das áreas de atuação do Campus Brasília, juntamente com um breve estudo das possibilidades de inserção dos egressos no mundo do trabalho, tomando como referência informações contidas nos planos de curso técnicos, elaborados pelo conjunto de docentes do Campus.

\title{
2.4.1 Contexto da área de Hospitalidade e Lazer
}

Brasília desenvolveu nas últimas décadas, forte vocação para o segmento de turismo de negócios e eventos, os quais são responsáveis por contribuições ao desenvolvimento local. 
A Confederação Brasileira de Convention \& Visitors Bureau ${ }^{1}$, no Brasil, contratou pesquisa em que foi evidenciado que em termos de geração de empregos, os espaços de eventos contratam em média sete funcionários fixos para cada empreendimento. As empresas organizadoras e entidades promotoras contratam em média 24,2 empregados fixos e 386,6 empregados temporários, perfazendo um universo 657.280 postos de trabalho (164.320 empregos diretos e 492.960 indiretos).

Ainda por esta pesquisa a cidade possui mais de 460 espaços para a realização de eventos. Os profissionais desta área atuam em empresas organizadoras de eventos, as empresas de cerimonial, os espaços de eventos, os locais de lazer, meios de hospedagem, instituições públicas e privadas, restaurantes, buffet, agências de turismo, além dos grandes eventos que vêm sendo captados pelo Brasil.

Segundo dados do Instituto Brasileiro de Geografia e Estatística (IBGE) de 2008, o Produto Interno Bruto (PIB) per capita do DF, cresce em média a $10 \%$ ao ano, o que demonstra o potencial do mercado de eventos na capital.

\subsubsection{Contexto da área de Serviço Público}

Pelo significativo papel que ocupa no cenário do Governo Federal, Brasília é conhecida como a Capital do Serviço Público, portanto com forte atuação no Arranjo Produtivo Local. Significativa parcela da população residente no Distrito Federal ocupa cargos públicos e muitas vagas são preenchidas constantemente nesse setor.

Um dos objetivos centrais da oferta de formação na área de Gestão Pública é garantir uma qualificação ao serviço público em suas esferas Federal, Distrital, Estadual ou municipal executando operações decorrentes de programas e projetos de políticas públicas, executando as funções de apoio administrativo, auxiliando na organização dos recursos humanos e materiais e utilizando ferramentas de informática.

O profissional com formação em Técnico de Serviços Públicos poderá atuar também em instituições de prestadores de serviços nas esferas federal, estadual, distrital ou municipal ou instituições sem fins lucrativos, que desenvolvem atividades ligadas à promoção do bem estar social, desenvolvimento regional, pesquisa aplicada e inovação tecnológica.

\footnotetext{
${ }^{1}$ Site: http://www.cbcvb.org.br/. Acesso em: 12 mar. 2016.
} 


\subsubsection{Contexto da área de Informática}

Há alguns anos, muito motivado pela instalação da estrutura do serviço público federal, o Distrito Federal tem sediado grandes empresas nacionais da área da Tecnologia da Informação e de vários portes, que buscam atender ao mercado e conquistar nichos internacionais. O APL de tecnologia da informação do DF apresenta continuamente um gargalo de escassez de mão-de-obra, tanto em qualidade quanto em quantidade.

Também é insatisfatória para a demanda existente a quantidade de centros tecnológicos que desenvolvam pesquisas, certifiquem produtos e atendam e apoiem pequenas empresas.

Segundo informação do Plano de Curso da área, estudo realizado pela consultoria International Data Corporation (IDC) ${ }^{2}$ aponta que no período de 2006 até 2009, pelo menos 630 mil profissionais em Tecnologia da Informação seriam contratados na América Latina, a maior parte no Brasil (35\%), que em 2010 já empregava 892 mil pessoas na área.

Como estratégia para atender esta carência, muitas empresas acabam se associando a escolas para abrir cursos e contratar os melhores alunos. São diversas as razões desta carência de mão-de-obra especializada, porém os cursos disponíveis atualmente não formam profissionais empregáveis, somado ao nível de conhecimento exigido pelo mercado que tem sido muito maior do que o entregue.

De acordo com os dados da Secretaria de Planejamento do Distrito Federal (SEPLAN/CODEPLAN), em 2010, do total de empregos gerados pela indústria no DF, o setor de Tecnologia da Informação e da Comunicação (TIC) é responsável por 36\%, abaixo apenas da construção civil com 42\%. Isso representava há época, 33.000 empregos e um faturamento anual de R\$ 4 bilhões. A maior concentração de empreendimentos está nas regiões do Plano Piloto, Guará, Taguatinga e Cruzeiro. As atividades mais expressivas e requisitadas dentro do setor de Tecnologia da Informação são as de consultoria em sistemas de informática, desenvolvimento de programas e as atividades de manutenção.

A perspectiva da instalação do Parque Tecnológico Capital Digital, com previsão de 10 empresas âncoras, espera-se gerar uma demanda de 80 mil empregos diretos e indiretos.

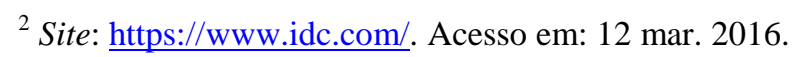


PARTE II 


\section{REFERENCIAL METODOLÓGICO}

Apresentado o referencial teórico da pesquisa empreendida, neste capítulo serão explicitados: o campo de pesquisa, ou seja, o universo, a amostra e identificação dos grupos de tratado e controle, o banco de dados com sua distribuição e composição, o método de pesquisa de diferenças em diferenças, com seu efeito médio de tratamento e estimação por dados em painel e, os instrumentos de pesquisa e coleta de dados, através das fichas de matrículas e modelo de questionário.

Por fim, serão ainda apresentados o modelo conceitual teórico utilizado e as limitações encontradas para a realização da pesquisa.

Essencialmente de abordagem quantitativa, visto que apurou o resultado de cada conjunto de dados, esta pesquisa adotou os anos de 2011 e 2012 como referências, por esta característica a pesquisa também é classificada como transversal, pois apresenta os resultados e a situação dos dados em determinado período de tempo (COOPER; SCHINDLER, 2003).

\subsection{DEFINIÇÃO DO CAMPO DE PESQUISA}

Este estudo foi realizado no âmbito do Campus Brasília do Instituto Federal de Brasília, tendo como base de pesquisa todos os alunos egressos, concluintes e evadidos, dos cursos técnicos para as três áreas de oferta da unidade: Hospitalidade e Lazer, Serviços Públicos e Informática, que ingressaram nos períodos de 2011 e 2012, conforme Quadro 01.

Cabe registrar que para efeito de conceito, adotou-se o significado da expressão egresso utilizada pela maioria dos dicionários, ou seja, aluno egresso é aquele que pertenceu ao quadro de alunos do IFB e que se afastou, retirou ou concluiu, ou seja, que de alguma forma deixou de pertencer.

O Instituto Federal de Brasília é uma instituição de ensino ainda em processo de implantação e organização interna. Até o momento da coleta dos dados, não possuía um sistema de registro acadêmico com informações de cadastro informatizado. Desta forma, os dados foram coletados através de consulta aos arquivos de fichário impresso de alunos. Após 
selecionados, todos os dados foram digitados em tabelas eletrônicas, totalizando uma população de 516 alunos egressos, distribuídos conforme Quadro 01.

Quadro 01 - Distribuição dos alunos egressos, concluintes e evadidos dos cursos técnicos do Campus Brasília, por ano de ingresso

\begin{tabular}{|l|c|c|c|c|c|c|}
\hline & \multicolumn{2}{|c|}{2011} & \multicolumn{2}{c|}{2012} & \multicolumn{2}{c|}{ TOTAIS } \\
\hline Condição do aluno & Concluintes & Evadidos & Concluintes & Evadidos & Concluintes & Evadidos \\
\hline Serviços Públicos & 21 & 55 & 17 & 87 & 38 & 142 \\
\hline Informática & 09 & 97 & 04 & 44 & 13 & 141 \\
\hline $\begin{array}{l}\text { Hospitalidade } \\
\text { Lazer }\end{array}$ & 16 & 61 & 27 & 78 & 43 & 139 \\
\hline Total por ano & 46 & 213 & 48 & 209 & 94 & 422 \\
\hline
\end{tabular}

Fonte: Elaborado pelo pesquisador com base nos dados dos arquivos do Registro Acadêmico do Campus

Considerando que o início das atividades do IFB Campus Brasília foi o ano de 2009 e que o tempo médio de duração dos cursos é de 18 a 24 meses para conclusão, foram adotados como períodos de pesquisa os anos de 2011 e 2012. Embora tenha sido considerado no projeto inicial o ano de 2013, este foi excluído desta pesquisa, visto que para análise dos egressos concluintes, o intervalo entre conclusão e coleta de informações seria de apenas seis meses.

Por não apresentar oferta de cursos técnicos neste período, não foi considerada no campo da pesquisa a área de Dança que também compõe uma das áreas de conhecimento e oferta do Campus Brasília.

Cabe esclarecer que o processo de seleção utilizado pelo Instituto Federal de Brasília, possibilita o amplo acesso de qualquer candidato a vaga, que atenda os critérios dos editais, visto que as inscrições podem ser realizadas presencialmente ou pela internet, sem cobrança de qualquer taxa de inscrição, eliminando assim a seleção por critérios econômicos. A forma de seleção dos inscritos se dá por meio de sorteio público de vagas, o que torna possível o ingresso de qualquer candidato inscrito, eliminando assim alguns vieses de seleção, comumente presentes em pesquisas com alunos egressos. 


\subsubsection{Identificação dos Grupos de Tratados e de Controle - Estratégica Empírica}

Foram considerados para efeito desta pesquisa como egressos todos os alunos que registrados como alunos no Campus Brasília, independente de efetivamente concluírem ou não os estudos regulares, estágios e outras atividades previstas no plano de curso e diplomados.

Para aplicação desta pesquisa, os grupos de tratados e de controle envolvidos foram assim constituídos: o de Tratados foi composto pelos alunos egressos concluintes dos cursos técnicos ofertados pelo Campus Brasília e o grupo de controle foi composto pelos alunos que evadiram ao longo do período do curso. Foram considerados evadidos, os alunos que apresentaram desistência ou tiveram suas matrículas por qualquer motivo canceladas durante o curso.

Cabe destacar que esse não é o grupo de controle ideal, tendo em vista que os alunos que evadiram poderiam estar promovendo autosseleção, o grupo ideal seria o de candidatos às vagas que não foram contemplados, ou seja, que não obtiveram êxito no processo de sorteio destas. Esta foi a situação inicialmente planejada, entretanto não foi possível dispor desse conjunto de dados. Observe que esse possível viés de autosseleção pode trazer resultados inesperados quando se compara os efeitos entre os grupos de tratamento e controle.

Foram desconsiderados nesta pesquisa, os alunos que estão em curso ou solicitaram o trancamento de matrícula, assim como alunos com pendência de atendimento do estágio curricular. Esta decisão foi adotada, pois os dados e informações para este grupo de alunos apresentam muitas inconsistências. Esta decisão gerou perdas informacionais para o grupo de controle.

Os cursos do Campus Brasília em avaliação são objeto de interesse de diferentes grupos, ou seja, contempla mulheres e homens em diferentes faixas etárias. Esta heterogeneidade dos grupos avaliados possibilitou a riqueza desta avaliação, visto que poderá permitir a indicação de estratégias e de aperfeiçoamento para diferentes características de grupos socioeconômicos. 


\subsection{BASE DE DADOS}

\subsubsection{Levantamento do Banco de Dados}

Segundo Foguel (2012), um dos principais problemas da área de avaliação de impacto é definir adequadamente os grupos envolvidos neste modelo de pesquisa. Definir um grupo de controle que represente adequadamente o contra fatual do grupo tratado, ou seja, um grupo de comparação que seja o mais próximo possível do que teria ocorrido com o grupo tratado caso este não tivesse recebido a intervenção.

Para definição do grupo de tratados, portanto egressos, realizou-se o levantamento das listas de concluintes para os quais foram emitidas as diplomações pelo Registro Acadêmico do Campus. No caso do grupo de controle, foram apurados nas listas de matrículas do primeiro semestre os alunos que evadiram ou solicitaram cancelamento. Após esta definição, foram recolhidas e digitadas as seguintes informações: nome completo, ano de conclusão, curso realizado, telefones (fixo e/ou celular), e-mail e endereço completo, informações retiradas da Ficha de Matrícula do aluno (Anexo 1).

Esta pesquisa buscou atingir toda a população de alunos egressos, que ingressaram nos anos de 2011 e 2012, nas condições definidas para a pesquisa. Após a seleção dos registros iniciais dos alunos, foram encaminhados pedidos de informações complementares por meio de mensagens eletrônicas.

$\mathrm{Na}$ primeira etapa foram encaminhadas mensagens eletrônicas para todos os alunos egressos. Como chave de controle das respostas, foi utilizado o endereço de e-mail do respondente, que era solicitado como informação inicial. Esta mensagem eletrônica (Anexo 2) remetia ao questionário eletrônico (Anexo 3), que solicitou demais informações e confirmação das informações existentes, anteriormente coletadas nas fichas de matrícula. Este procedimento foi adotado em três etapas de remessas de mensagens eletrônicas de solicitação de dados, com intervalos de 15 dias entre elas.

Deste processo de consulta eletrônica, foram obtidos inúmeros retornos com endereços de e-mail inválidos ou com erros de digitação. Paralelamente ao período de aguardo de respostas, foram pesquisados por meio de redes sociais e de contatos pessoais de diversos docentes do Campus, dados corretos de e-mail de alunos. Após a obtenção das informações foram novamente encaminhados os e-mails. Foram contatados também, via 
telefone, alguns alunos que ocuparam alguma função como representantes de turma, a fim de validar mais algumas informações de $e$-mail.

Inicialmente o projeto de pesquisa, previa uma segunda etapa de remessa de questionários impressos via postal com envelopes e porte postal para resposta, e uma terceira etapa de coleta de informações, via telefone, a fim de obter a totalidade da população a ser pesquisada. Ao longo da realização da pesquisa, estas possibilidades se tornaram inviáveis em razão dos prazos de execução e de recursos financeiros, uma vez que a pesquisa não obteve qualquer fonte de financiamento.

Assim, transcorridos 60 dias e como não foram obtidas mais respostas, a pesquisa passou a considerar a amostragem como parâmetro, adotando a técnica de saturação da amostra. Segue no Quadro 2, a composição do banco de dados final de alunos egressos utilizado nesta pesquisa, com base nas respostas obtidas dos questionários de informações, totalizando 135 respostas, o que corresponde a 26,16 \% da população de alunos egressos.

Quadro 02 - Distribuição do banco de dados, de alunos egressos que responderam ao questionário de informações

\begin{tabular}{|l|c|c|c|c|c|c|}
\hline & \multicolumn{2}{|c|}{2011} & \multicolumn{2}{c|}{2012} & \multicolumn{2}{c|}{ TOTAIS } \\
\hline $\begin{array}{l}\text { Condição do } \\
\text { aluno }\end{array}$ & Concluintes & Evadidos & Concluintes & Evadidos & Concluintes & Evadidos \\
\hline $\begin{array}{l}\text { Serviços } \\
\text { Públicos }\end{array}$ & 15 & 13 & 04 & 18 & 19 & 31 \\
\hline $\begin{array}{l}\text { Informática } \\
\text { Hospitalidade } \\
\text { e Lazer }\end{array}$ & 07 & 22 & 05 & 11 & 12 & 33 \\
\hline Total por ano & 29 & 44 & 22 & 40 & 20 & 20 \\
\hline
\end{tabular}

Fonte: Elaborado pelo pesquisador com base no número de questionários respondidos

Comparando os Quadros 1 e 2, verifica-se que se tem maior representação amostral no curso de informática com $92 \%$ para o grupo dos concluintes e $23 \%$ do grupo dos evadidos, enquanto que a menor representação está no curso de Hospitalidade e Lazer com $46 \%$ dos concluintes e $14 \%$ dos evadidos. O Quadro 3 apresenta esta relação de representatividade da amostra. 
Quadro 03 - Percentual amostral da pesquisa em relação a população por grupo de concluintes e evadidos e ano

\begin{tabular}{|l|c|c|c|c|c|c|}
\hline \multirow{2}{*}{$\begin{array}{c}\text { Condição do } \\
\text { aluno/Cursos/Ano } \\
\text { de Ingresso }\end{array}$} & Concluintes & Evadidos & Concluintes & Evadidos & Concluintes & Evadidos \\
\cline { 2 - 7 } & & \multicolumn{2}{|c|}{2011} & & \multicolumn{2}{c|}{ TOTAIS } \\
\hline Serviços Públicos & $71,4 \%$ & $23,6 \%$ & $23,5 \%$ & $20,7 \%$ & $50,0 \%$ & $21,8 \%$ \\
\hline Informática & $77,8 \%$ & $22,7 \%$ & $80,0 \%$ & $25,0 \%$ & $92,3 \%$ & $23,4 \%$ \\
\hline Hospitalidade & $43,8 \%$ & $14,8 \%$ & $48,1 \%$ & $14,1 \%$ & $46,5 \%$ & $14,4 \%$ \\
\hline Lazer & $63,0 \%$ & $20,7 \%$ & $45,8 \%$ & $19,1 \%$ & $54,3 \%$ & $19,9 \%$ \\
\hline Total por ano & & & & & & \\
\hline
\end{tabular}

Fonte: Elaborado pelo pesquisador com base nos dados dos arquivos do Registro Acadêmico do Campus

Assim identificamos uma participação percentual maior de respostas de egressos concluintes, ainda que na totalidade da população seja menor, o que se explique pelo esforço em contatos através de redes sociais e de arquivos de docentes do Campus de Brasília.

\subsubsection{Composição das informações do Banco de Dados}

No Quadro 4, a seguir detalhado, estão relacionadas às variáveis selecionadas para compor o banco de dados: o dado, detalhamento da variável e sua fonte. Além da relação com o objetivo do projeto, as variáveis foram selecionadas observando a disponibilidade e qualidade da informação, conforme Ficha de Matrícula do Registro Acadêmico do Campus (Anexo 1) e de acordo com a possibilidade de obtenção através da aplicação do questionário.

Quadro 4 - Variáveis do Banco de Dados

\begin{tabular}{|l|l|l|}
\hline \multicolumn{1}{|c|}{ VARIÁVEL } & \multicolumn{1}{|c|}{ DETALHAMENTO DA VARIÁVEL } & \multicolumn{1}{c|}{ FONTE } \\
\hline Curso & $\begin{array}{l}\text { Conforme as três áreas de atuação do Campus: } \\
\text { Serviços Públicos (SP); Informática (IN) e } \\
\text { Hospitalidade e Lazer (HL). }\end{array}$ & Ficha de matrícula \\
\hline Aluno & Matrícula escolar & Registro acadêmico \\
\hline
\end{tabular}




\begin{tabular}{|c|c|c|}
\hline Ano & Ano de matrícula & Ficha de matrícula \\
\hline Turno & $\begin{array}{l}\text { Período de realização do curso: Matutino (MAT); } \\
\text { Vespertino (VES) ou Noturno ((NOT) }\end{array}$ & Ficha de matrícula \\
\hline Condição do Egresso & $\begin{array}{l}\text { Condição de Tratamento: } 0 \text { - Aluno egresso evadido } \\
\text { ou não concluinte e } 1 \text { - aluno egresso concluinte, que } \\
\text { concluiu o curso }\end{array}$ & Registro acadêmico \\
\hline E-mail & Endereço de e-mail & Ficha de matrícula \\
\hline Telefone & Número de Telefone & Ficha de matrícula \\
\hline Endereço & Endereço completo com CEP & Ficha de matrícula \\
\hline Sexo & Identificação de gênero & Ficha de matrícula \\
\hline Naturalidade & Apenas o Estado de origem & Ficha de matrícula \\
\hline Ano Nascimento & Identificação do ano de nascimento & Ficha de matrícula \\
\hline Raça/Etnia & Raça/Etnia declarada na ficha de matrícula & Ficha de matrícula \\
\hline $\begin{array}{l}\text { Idade de conclusão do } \\
\text { Ensino Médio }\end{array}$ & $\begin{array}{l}\text { Diferença entre o ano de nascimento e o ano de } \\
\text { conclusão do ensino médio. }\end{array}$ & Ficha de matrícula \\
\hline $\begin{array}{l}\text { Idade de Ingresso no } \\
\text { Curso Técnico }\end{array}$ & $\begin{array}{l}\text { Diferença entre o ano de nascimento e o ano de } \\
\text { ingresso no IFB }\end{array}$ & Ficha de matrícula \\
\hline Intervalo de estudos & $\begin{array}{l}\text { Tempo de intervalo entre os estudos, calculado entre o } \\
\text { ano de conclusão do Ensino Médio e o ano de ingresso } \\
\text { no Curso Técnico }\end{array}$ & Ficha de matrícula \\
\hline Situação Trabalho 01 & $\begin{array}{l}\text { Condição de trabalho, no ano de matrícula } \\
01 \text { - Empregado ou } 02 \text { - Desempregado }\end{array}$ & Ficha de matrícula \\
\hline Situação Trabalho 02 & $\begin{array}{l}\text { Condição de trabalho, em resposta ao questionário } \\
01 \text { - Empregado ou } 02 \text { - Desempregado }\end{array}$ & Questionário \\
\hline Renda Familiar 01 & $\begin{array}{l}\text { Valor da renda familiar inicial, declarado na ficha de } \\
\text { matrícula, no ano de matrícula. }\end{array}$ & Ficha de matrícula \\
\hline Renda Familiar 02 & $\begin{array}{l}\text { Valor da renda familiar atual, declarado em resposta ao } \\
\text { questionário, no ano da pesquisa. }\end{array}$ & Questionário \\
\hline Renda Individual 01 & $\begin{array}{l}\text { Valor da renda individual inicial no ano de ingresso, } \\
\text { declarado em resposta ao questionário, no ano da } \\
\text { pesquisa. }\end{array}$ & Questionário \\
\hline Renda Individual 02 & $\begin{array}{l}\text { Valor da renda individual atual, declarado em resposta } \\
\text { ao questionário, no ano da pesquisa. }\end{array}$ & Questionário \\
\hline $\begin{array}{l}\text { Composição Familiar } \\
01\end{array}$ & $\begin{array}{l}\text { Número de pessoas que compõe o núcleo familiar, no } \\
\text { ano de matrícula. }\end{array}$ & Ficha de matrícula \\
\hline Composição Familiar & Número de pessoas que compõe o núcleo familiar & Questionário \\
\hline
\end{tabular}




\begin{tabular}{|l|l|l|}
\hline 02 & atualizado, em resposta ao questionário. & \\
\hline Filhos 01 & Quantidade de filhos, no ano de matrícula. & Ficha de matrícula \\
\hline Filhos 02 & Quantidade de filhos, em resposta ao questionário. & Questionário \\
\hline Procedência Escolar & $\begin{array}{l}\text { Identificação do tipo de escola de origem: pública ou } \\
\text { privada }\end{array}$ & Ficha de matrícula \\
\hline $\begin{array}{l}\text { Ano de conclusão do } \\
\text { Ensino Médio }\end{array}$ & Identificação do ano de diplomação do ensino médio & Ficha de matrícula \\
\hline $\begin{array}{l}\text { Formação Escolar da } \\
\text { Mãe }\end{array}$ & $\begin{array}{l}\text { Nível de Escolaridade da mãe: 0 - Analfabeta; 1 - } \\
\text { Fundamental; 2 - Médio; 3 - Técnica; 4 - Superior e 5 - } \\
\text { Pós Graduada }\end{array}$ & Questionário \\
\hline $\begin{array}{l}\text { Formação Escolar do } \\
\text { Pai }\end{array}$ & $\begin{array}{l}\text { Nível de Escolaridade do pai: 0 - Analfabeto; 1 - } \\
\text { Fundamental; 2 - Médio; 3 - Técnica; 4 - Superior e 5 - } \\
\text { Pós Graduado }\end{array}$ & Questionário \\
\hline $\begin{array}{l}\text { Maior nível de } \\
\text { escolaridade entre os } \\
\text { pais }\end{array}$ & $\begin{array}{l}\text { Maior nível de formação entre as informações de de } \\
\text { escolaridade do pai e da mãe }\end{array}$ & Questionário \\
\hline $\begin{array}{l}\text { Avaliação do aluno em } \\
\text { relação } \\
\text { educativa a oferta }\end{array}$ & $\begin{array}{l}\text { Informação de percepção do aluno em relação à oferta } \\
\text { educativa: Ótimo, bom, regular, ruim, péssimo e não } \\
\text { opinou }\end{array}$ & Questionário \\
\hline
\end{tabular}

Fonte: Elaborado pelo pesquisador com base em informações da Ficha de Matrícula e Questionário

Também foram coletados por meio do questionário, alguns dados complementares e de percepção dos alunos, que não foram contemplados diretamente na análise dos objetivos da pesquisa.

Quadro 5 - Informações complementares e de percepção coletados no Questionário

\begin{tabular}{|l|l|l|}
\hline \multicolumn{1}{|c|}{ VARIÁVEL } & \multicolumn{1}{|c|}{ DETALHAMENTO DA VARIÁVEL } & FONTE \\
\hline $\begin{array}{l}\text { Formação profissional } \\
\text { anteriores ao ingresso no } \\
\text { IFB }\end{array}$ & $\begin{array}{l}\text { Já possuía ou não algum curso de formação } \\
\text { profissional, antes de ingressar no IFB. Curso de } \\
\text { curta duração ou formação profissional inicial, } \\
\text { outro curso técnico ou Ensino Superior }\end{array}$ & Questionário \\
\hline $\begin{array}{l}\text { Formação profissional } \\
\text { após ingresso no IFB }\end{array}$ & $\begin{array}{l}\text { Participou ou não de outro curso de formação } \\
\text { profissional, após o ingresso no IFB. Curso de } \\
\text { curta duração ou formação profissional inicial, } \\
\text { outro curso técnico ou Ensino Superior }\end{array}$ & Questionário \\
\hline
\end{tabular}




\begin{tabular}{|c|c|c|}
\hline $\begin{array}{l}\text { Situação de vínculo de } \\
\text { trabalho quando } \\
\text { ingresso no IFB }\end{array}$ & $\begin{array}{l}\text { Situação vínculo inicial com o mundo do trabalho, } \\
\text { quando do ingresso no IFB: Desempregado, } \\
\text { empregado sem carteira assinada, empregado com } \\
\text { carteira assinada, contrato temporário, servidor } \\
\text { público, autônomo ou prestador de serviços, } \\
\text { estagiário, proprietário de empresa / negócio ou } \\
\text { outros }\end{array}$ & Questionário \\
\hline $\begin{array}{l}\text { Situação de vínculo de } \\
\text { trabalho atual }\end{array}$ & $\begin{array}{l}\text { Situação vínculo com o mundo do trabalho, quando } \\
\text { da resposta ao questionário: Desempregado, } \\
\text { empregado sem carteira assinada, empregado com } \\
\text { carteira assinada, contrato temporário, servidor } \\
\text { público, autônomo ou prestador de serviços, } \\
\text { estagiário, proprietário de empresa / negócio ou } \\
\text { outros. }\end{array}$ & Questionário \\
\hline $\begin{array}{l}\text { Percepção do valor da } \\
\text { remuneração/renda em } \\
\text { relação a atual formação }\end{array}$ & $\begin{array}{l}\text { Percepção da remuneração, considerando a atual } \\
\text { formação, em relação ao mundo do trabalho. } \\
\text { Abaixo, na média ou acima da média do mercado. } \\
\text { Não sabe ou não opinou }\end{array}$ & Questionário \\
\hline $\begin{array}{l}\text { Interesse de atuação na } \\
\text { área de formação }\end{array}$ & $\begin{array}{l}\text { Condição de interesse de atuação profissional na } \\
\text { área de formação do curso técnico que participou. }\end{array}$ & Questionário \\
\hline $\begin{array}{l}\text { Motivação da evasão ou } \\
\text { não conclusão }\end{array}$ & $\begin{array}{l}\text { Informação referente a motivação da evasão: } \\
\text { motivos familiares, distância ou dificuldade de } \\
\text { deslocamento, opção por outro curso, dificuldade } \\
\text { de conciliar horários, trabalho, não adaptação/ } \\
\text { interesse pelo curso, problemas de infraestrutura do } \\
\text { IFB e outros motivos }\end{array}$ & Questionário \\
\hline
\end{tabular}

Fonte: Elaborado pelo pesquisador com base em informações da Ficha de Matrícula e Questionário

Ao longo do desenvolvimento da pesquisa e com o foco na análise das rendas individuais e familiares, bem como na condição de empregabilidade, foram descartadas algumas proposições iniciais de dados e informações contidas no projeto inicial de pesquisa, que se entendeu como irrelevantes, tais como: tempo em meses de vínculo de emprego, relação entre a área de formação e atuação profissional, percepção da relevância da formação e da continuidade do itinerário formativo.

\subsection{MÉTODOS UTILIZADOS EM AVALIAÇÃO DE IMPACTO - DIFERENÇAS EM DIFERENÇAS}

Foguel (2012) afirma que os métodos de avaliação de impacto são divididos em dois grupos: experimental e não experimental. No grupo experimental ou grupo de referência, a escolha é baseada na seleção aleatória dos participantes e não participantes do programa, 
este grupo é considerado como o ideal para a área de avaliação, pois todos os participantes possuem a mesma condição. Esta não é uma condição muito simples de obtenção, pois normalmente há inúmeras variáveis que afetam e diferenciam os grupos de participantes e não participantes da pesquisa. É o caso desta pesquisa, pois não há uma condição de total igualdade de variáveis entre os participantes, estes podem apresentar diferenças de classes sociais, idades e histórico escolar, entre outros.

Para minimizar estas diferenciações é que foram desenvolvidos diferentes métodos não experimentais para uso em avaliações de impacto. E, um dos mais empregados é o Método Diferenças em Diferenças (diff-in-diff). Este método se baseia no cálculo de uma dupla subtração: a primeira se refere à diferença das médias da variável de resultado entre os períodos anterior e posterior ao programa ou política pública, para o grupo de tratamento e para o de controle, e a segunda se refere à diferença da primeira diferença calculada entre esses dois grupos. O Quadro 6 representa os grupos e as variáveis utilizadas nesta pesquisa.

Quadro 6 - Representação dos grupos utilizados na pesquisa a partir do Método Diferenças em Diferenças (Diff-in-diff)

\begin{tabular}{|l|c|c|c|}
\hline & $\begin{array}{c}\text { ANTERIOR } \\
2011 \text { E 2012 }\end{array}$ & $\begin{array}{c}\text { POSTERIOR } \\
\mathbf{2 0 1 5}\end{array}$ & DIFERENÇAS \\
\hline CONTROLE - Alunos Evadidos & A & B & C-D \\
\hline TRATAMENTO - Alunos Concluintes & C & D & ((C-D) - (A-B)) \\
\hline DIFERENÇAS & A-C & B-D & \\
\hline
\end{tabular}

Fonte: Elaborado pelo pesquisador.

Pelo exposto no Quadro 6, as diferenças entre A-B e C-D representam em que medida houve alteração entre os grupos de tratamento e controle, entre o período anterior e posterior à oferta educativa, enquanto A-C e B-D referem-se às diferenças entre os grupos de tratamento e controle, antes e depois da oferta educativa.

Ainda segundo Foguel (2012), uma das vantagens deste método, que se utiliza de informações para ambos os grupos para, pelo menos, um período de tempo antes e para um período depois do programa, é a capacidade de lidar com o viés de seleção associado a características não observáveis dos indivíduos, especificamente àquelas que são invariantes no tempo. 
A principal hipótese do Método de Diferenças em Diferenças é que a trajetória temporal da variável de resultado para o grupo de controle represente o que ocorreria com o grupo tratado caso não houvesse a intervenção, nesta pesquisa, estudar os resultados dos alunos egressos evadidos, que não concluíram a oferta ou formação profissional técnica e os alunos egressos concluintes, que concluíram a formação e obtiveram a diplomação.

Este método, também permite o controle de características não observáveis dos indivíduos que sejam invariantes no tempo, características estas que podem gerar viés de autosseleção, conferindo assim mais uma vantagem deste método não experimental.

O grande desafio de uma avaliação de impacto eficaz é encontrar o contra fatual ou grupo de controle para o grupo tratado, ou seja, o que teria ocorrido a esse grupo na ausência da intervenção. A ausência de uma boa seleção deste grupo pode tornar a pesquisa ingênua. Esta situação é bastante comum quando se compara o grupo de tratados antes e depois da intervenção, ou quando compara o grupo de tratados com um grupo qualquer de não tratados após a intervenção. Em ambos os casos não são observadas as demais variáveis que afetam o resultado da análise.

O Método de Diferenças em Diferenças busca contornar esta situação ingênua, quando encontra um grupo de comparação que mais se pareça com o grupo tratado, sendo este um grupo também sujeito as mesmas influências dos fatores que afetam a variável de resultado dos tratados. Como já citado, a condição ideal para definição do grupo de comparação para esta pesquisa seria os alunos que fizeram a inscrição e não obtiveram êxito na seleção através do processo de sorteio de vagas. No entanto, pela deficiência da informação para efeito desta pesquisa foram utilizados como grupo de comparação os alunos egressos que evadiram ou não concluíram a formação.

O método busca também encontrar um grupo de indivíduos para os quais a evolução da variável de resultado corresponda à trajetória dessa variável para o grupo tratado na ausência do programa, para tanto é necessário obter informações em quantidade e com qualidade. Uma das formas de testar a qualidade desta informação é aplicar testes de tendência temporal da variável de resultado dos dois grupos seja a mesma antes do programa, este procedimento garante uma maior credibilidade aos resultados obtidos. No caso desta pesquisa, esse teste não foi possível, mas houve uma condição clara de aleatorização no processo de seleção, através do sorteio público de vagas. 
Quanto aos dados utilizados neste método, estes podem ser em painel, quando tratam de informações seguidas em determinado período, ou dados seccionais, dados repetidos no tempo calculado por meio de médias. Para efeito desta pesquisa, os dados foram apresentados em painel, utilizando informações do período de matrícula e do período de coleta de informações pelo questionário (Anexo 3).

\subsubsection{O efeito médio do tratamento para os tratados}

Inicialmente é necessário considerar que não apenas o fator formação, ou seja, o fato do grupo de tratados terem tido acesso aos cursos técnicos é determinante no resultado do seu processo de garantia de inserção no mundo do trabalho e de aumento de renda. No entanto é possível afirmar que o efeito desta formação sobre o grupo de tratados, reafirma um interesse dos indivíduos do grupo, que buscaram esta formação como alternativa de diferenciação no mundo do trabalho, podendo inclusive ser este um fator determinante do sucesso dos mesmos. Portanto, o que pode ser afirmado é que já havia mesmo antes da formação uma pré-disposição em buscar a empregabilidade ou aumento de renda, e que a qualificação profissional, pode ser um dos elementos a este processo. Analisar e propor a dimensão destes elementos foi um dos desafios deste estudo.

No que diz respeito ao grupo de controle, estes também apresentavam esta prédisposição quando da concorrência às vagas. A partir destas afirmativas, afere-se que a formação recebida possa ser um dos diferenciais entre os grupos, isto nos permite afirmar que a princípio numa situação de experimento natural, os resultados da formação podem impactar diretamente nos resultados entre os dois grupos.

Desta forma, podemos apresentar este efeito médio do tratamento sobre os alunos egressos a partir da proposição da seguinte equação:

$$
\begin{aligned}
& \mathrm{ATT}=\mathrm{E}\left\{\mathrm{Y}_{1} / T=1, t=04\right\}-\mathrm{E}\left\{\mathrm{Y}_{0} / T=0, t=04\right\}- \\
& {\left[\mathrm{E}\left\{\mathrm{Y}_{1} / T=1, t=00\right\}-\mathrm{E}\left\{\mathrm{Y}_{0} / T=0, t=00\right\}\right]}
\end{aligned}
$$

Em que:

- ATT é o efeito médio do tratamento para os tratados; 
- $\mathrm{E}\left\{\mathrm{Y}_{1} / T=1, t=04\right\}$ é a média da variável resultado para os alunos egressos concluintes após a formação;

- $\mathrm{E}\left\{\mathrm{Y}_{1} / T=1, t=00\right\}$ é a média da variável resultado para os alunos egressos concluintes antes da formação;

- $\mathrm{E}\left\{\mathrm{Y}_{\mathbf{0}} / T=0, \mathrm{t}=04\right\}$ é a média da variável resultado para os alunos egressos evadidos ou grupo de controle, no mesmo período de formação dos alunos egressos concluintes;

- $\mathrm{E}\left\{\mathrm{Y}_{\mathbf{0}} / T=0, t=00\right\}$ é a média da variável resultado para os alunos egressos evadidos ou grupo de controle, no mesmo período dos alunos egressos concluintes, antes da formação.

\subsubsection{Estimação por dados em painel com efeito fixo: dois períodos}

Na sequência, a hipótese de experimento natural foi abandonada, visto que a simples diferença de médias produz estimativas enviesadas para experimentos não aleatórios, tornando-se necessário o uso de métodos de regressão para separarmos os efeitos de variáveis - observáveis e/ ou não observáveis - do efeito puro da oferta de formação sobre os indivíduos do grupo de tratados.

O método de diferenças em diferenças utiliza-se da regressão com dados em painel para separar os efeitos de variáveis. Neste método, com dois períodos, são coletados dados nos períodos anteriores e posteriores à intervenção ou oferta de formação profissional, para cada unidade de observação, a partir deste passo é estimada uma regressão linear por Mínimos Quadrados Ordinários (MQO) para dados em painel com efeitos fixos entre os indivíduos pesquisados.

Wooldridge (2002) afirma como grande vantagem desse método que os dados de painel permitem que se estimem consistentemente efeitos de tratamento sem a suposição de ignorabilidade do tratamento e sem uma variável instrumental, fornece ainda respostas do tratamento sobre o tempo e é não correlacionado com variáveis não observáveis que variam no tempo e que afetam a resposta.

O pressuposto deste método é que os efeitos dos fatores não observáveis que influenciam as variáveis resultados mantêm-se constantes ao longo do tempo, supõem também que o efeito do tratamento é aditivo, isto é, que uma função linear é capaz de capturar o real efeito. 
O comportamento das variáveis de interesse pode ser apresentado através da seguinte equação:

$$
Y_{i s t}=\alpha+\Theta_{i}+Y t_{i}+\beta T_{i}+\delta X_{i t}+u_{\text {it }}
$$

Sendo:

$\alpha$ - é o termo de intercepto;

$\Theta_{i}$ - captura o efeito fixo específico para o indivíduo “i”;

$Y t_{i}$ - é o coeficiente que mede o efeito da dummy de tempo;

$\beta$ - captura o impacto da formação sobre a variável de interesse;

$\boldsymbol{T}$ - é uma variável dummy que identifica se o indivíduo está ou não sob tratamento;

$\boldsymbol{\delta}$ - é o vetor de coeficientes associados às variáveis independentes;

$\boldsymbol{X}_{\text {it }}$ - é a matriz de variáveis independentes para cada indivíduo pesquisado i, no tempo t; $\boldsymbol{u}_{\text {it }}$ - é o termo de erro.

A opção pela utilização de estimação por dados de painel em dois tempos ocorre em razão da disponibilidade dos dados no início da oferta, também considerado o tempo após a conclusão da formação, permitindo assim a avaliação de seus impactos.

\subsection{INSTRUMENTOS DE PESQUISA}

Como instrumentos de pesquisa, para a obtenção das informações que compuseram esta pesquisa, foram adotadas as Fichas de Matrículas de alunos e o questionário. 


\subsubsection{Fichas de Matrícula}

Para a seleção dos dados iniciais, com as informações dos dois grupos da pesquisa, foi adotada a Ficha de Matrícula de Alunos do IFB, conforme Anexo 1. Esta ficha é preenchida e entregue com a documentação no ato da matrícula no primeiro semestre de curso.

Considerando a ausência de dados informatizados no Registro Acadêmico do Campus Brasília para a apuração e tabulação dos dados destas fichas, foram realizadas pesquisas na documentação impressa nas pastas de alunos do fichário da unidade, o que demandou um significativo tempo para a coleta de dados.

\subsubsection{Questionário}

Além da coleta e tabulação de dados das Fichas de Matrícula, existentes no setor de Registro Acadêmico do Campus Brasília, também foi adotado um questionário para obtenção e atualização dos dados inicialmente informados (Anexo 3).

Gil (2008) define o questionário como uma “[...] técnica de investigação composto por um conjunto de questões que são submetidas a pessoas com o propósito de obter informações sobre conhecimentos, crenças, sentimentos, valores, etc.” (p. 121).

Para a elaboração do questionário foram adotadas questões que permitiram a obtenção de informações para realizar análises e avaliações sobre o tema da inserção no mundo do trabalho e aumento de renda. Neste processo, foram consideradas as seguintes abordagens:

a) dados de perfil e sócio econômicos dos alunos: gênero, raça, formação educacional básica, antecedentes familiares e situação socioeconômica do núcleo familiar;

b) dados sobre a sua situação de inserção no mundo do trabalho, tais como: identificação da situação de emprego ou não, vinculação formal ou informal de trabalho, interesse de atuação na área e renda individual; 
c) dados e percepções em relação à oferta educacional, informações como: histórico de formação antes e após a oferta educacional, percepção da relação entre formação e renda e avaliação da formação recebida.

O questionário possibilitou também por meio de uma questão final aberta, o registro de considerações, comentários ou sugestões a respeito da pesquisa ou da oferta educativa realizada pelo aluno no Instituto Federal de Brasília.

\subsection{LIMITAÇÕES ENCONTRADAS PARA REALIZAÇÃO DA PESQUISA}

Ao longo da execução desta pesquisa foram identificadas algumas limitações que impactaram na qualidade e resultados do estudo.

A primeira evidência de limitação diz respeito à disponibilidade de dados dos alunos no sistema de registros do Campus Brasília. Os dados foram coletados de forma manual, não houve utilização de sistemas informatizados de registro de dados, por consequência, em alguns casos foram observados a não utilização de padrões na coleta de informações entre os servidores, ou seja, muitas informações incompletas. Esta limitação demandou um excessivo período de tempo de desenvolvimento da pesquisa.

Para além da incompletude de dados ou ausência de padrão de informações, a quantidade de variáveis disponíveis em especial de variáveis socioeconômicas para execução de uma pesquisa social, foi insuficiente. Para sanar esta limitação, recorreu-se a utilização de informações recordatórias, isto é, a utilização de informações declaradas pelos alunos egressos com base em fatos de dois ou três anos anteriores, portanto bastante sujeito a inconsistência nas respostas.

A ausência de série histórica foi outra limitação observada, desejável nos casos de utilização de dados em painel. Foram utilizados dois anos de ingresso de alunos, 2011 e 2012, não sendo possível utilizar períodos anteriores, pois, o Campus Brasília iniciou suas atividades em 2009 com um número reduzido de alunos. Também não foi possível utilizar períodos posteriores, pois foram identificados muitos alunos ainda em curso, somado ao fato do intervalo de tempo de egresso por conclusão, portanto para inserção no mundo do trabalho, ser inferior a 12 meses para aqueles que concluíram. 
A pesquisa identificou que o cenário de análise ideal contemplaria a coleta de dados em quatro momentos, deste modo uma análise de dados em painel em quatro períodos. Admitiu-se como situação a coleta de dados: quando da inscrição no processo seletivo, na data de saída por conclusão dos concluintes, para ambos os grupos e dois intervalos mínimos de dois anos após o período de saída.

Ainda projetando o cenário ideal para a pesquisa, o melhor grupo de controle ou de comparação para esta pesquisa seria os alunos que fizeram a inscrição e não obtiveram êxito na seleção através do processo de sorteio de vagas. No entanto, como já explicitado, pela deficiência da informação para efeito desta pesquisa foram utilizados como grupo de comparação os alunos egressos que evadiram ou não concluíram a formação.

Sugere-se a observação, adoção e correção destas limitações para as próximas pesquisas com mesmo escopo e objetivos. 
PARTE III 


\section{RESULTADOS OBTIDOS}

Seção em que são apresentados os principais resultados que, para atender aos objetivos desta pesquisa, foram apresentados em três tópicos: perfil do aluno egresso do Instituto Federal de Brasília a partir do instrumento de pesquisa; análise da situação de empregabilidade dos alunos; e, análise dos impactos da formação, a partir da análise de informações entre os grupos de tratados e grupo de controle.

\subsection{PERFIL PREDOMINANTE DO ALUNO EGRESSO DO INSTITUTO FEDERAL DE BRASÍLIA}

Considerando as informações disponíveis no banco de dados, o Quadro 7, detalha o perfil predominante do aluno egresso, a partir das respostas a pesquisa.

Quadro 7 - Perfil predominante do aluno egresso participante da pesquisa

\begin{tabular}{|c|c|c|c|c|}
\hline VARIÁVEL & \multicolumn{2}{|c|}{ PERFIL PREDOMINANTE } & EGRESSOS & EGRESSOS \\
\hline Gênero & Feminino & $60 \%$ & $44,45 \%$ & $55,55 \%$ \\
\hline Cor / Raça & Parda & $51,11 \%$ & $28,98 \%$ & $71,02 \%$ \\
\hline Procedência Escolar & Pública & $85,19 \%$ & $38,26 \%$ & $61,74 \%$ \\
\hline Origem & Do DF & $59,25 \%$ & $33,75 \%$ & $66,25 \%$ \\
\hline Faixa Etária & De 15 a 24 anos & $28,89 \%$ & $35,89 \%$ & $64,11 \%$ \\
\hline Região Moradia & $\begin{array}{l}\text { Fora Plano Piloto, demais } \\
\text { Regiões Administrativas do } \\
\text { DF e Entorno }\end{array}$ & $80,75 \%$ & $62,61 \%$ & $37,39 \%$ \\
\hline
\end{tabular}

Fonte: Elaborado pelo pesquisador.

Assim, observa-se que o perfil do aluno analisado nesta pesquisa, detalhado no Quadro 7, é formado por mulheres brasilienses, pardas, de primeira faixa etária econômica produtiva, oriundas de escolas públicas e residentes fora do Plano Piloto e entorno. 
Empiricamente, se observa que esta amostra é de fato representante da população de alunos do Campus Brasília, tal fato é motivado pela ofertado de cursos do campus, como Eventos e Serviços Públicos, que visivelmente são ocupados, em maioria, por alunas com este perfil.

\subsection{RELAÇÃO DOS EGRESSOS COM O MUNDO DO TRABALHO}

Um dos objetivos da Educação Profissional é promover mecanismos de inserção dos alunos no mundo do trabalho. Esta inserção não necessariamente deve caracterizar-se por condições de vínculo empregatício, mas de garantia de renda pelo trabalho. Os resultados apresentados na Tabela $1^{3}$, não podem ser aferidos exclusivamente a esta formação, mas podem ser considerados como uma das possibilidades de resultado da oferta educativa.

Da mesma forma, um dos objetivos desta pesquisa foi apurar a relação dos egressos com o Mundo do Trabalho. Aqui novamente as informações foram coletadas por meio de dados recordatórios, para a informação da situação inicial, isto é, o aluno egresso informou a partir lembrança da condição de vínculo dele com o mundo do trabalho no momento de ingresso no Instituto Federal de Brasília.

Para o levantamento desta formação foram utilizadas as seguintes perguntas:

a) Na ocasião em que iniciei meus estudos no IFB, em relação à minha situação de trabalho?

b) Qual a situação de trabalho atual?

Tabela 1 - Relação da situação de vínculo dos egressos com o mundo do trabalho

\begin{tabular}{|l|c|c|c|c|c|c|}
\hline $\begin{array}{c}\text { SITUAÇÃO } \\
\text { MUNDO } \\
\text { TRABALHO }\end{array}$ & \multicolumn{2}{|c|}{ EGRESSOS CONCLUINTES } & \multicolumn{3}{c|}{ EGRESSOS EVADIDOS } \\
\hline & ANTES & DEPOIS & VARIAÇÃO & ANTES & DEPOIS & VARIAÇÃO \\
\hline Desempregado & 52,95 & 25,49 & $-27,46$ & 36,90 & 20,24 & $-16,66$ \\
\hline $\begin{array}{l}\text { Empregado com } \\
\text { Registro }\end{array}$ & 21,57 & 29,42 & 7,85 & 35,72 & 40,48 & 4,76 \\
\hline
\end{tabular}

\footnotetext{
${ }^{3}$ Todas as tabelas da pesquisa foram elaboradas pelo pesquisador, com base nos dados coletados.
} 


\begin{tabular}{|l|c|c|c|c|c|c|}
\hline $\begin{array}{l}\text { Empregado sem } \\
\text { registro }\end{array}$ & 7,84 & 1,96 & $-5,88$ & 9,52 & 2,38 & $-7,14$ \\
\hline Contrato Temporário & 3,92 & 3,92 & 0 & 1,19 & 2,38 & 1,19 \\
\hline Servidor Público & 7,84 & 15,69 & 7,85 & 10,72 & 20,24 & 9,52 \\
\hline $\begin{array}{l}\text { Autônomo / } \\
\text { Prestador de Serviços }\end{array}$ & 3,92 & 7,84 & 3,92 & 3,57 & 5,95 & 2,38 \\
\hline Estagiário & 1,96 & 13,73 & 11,77 & 0 & 4,76 & 4,76 \\
\hline $\begin{array}{l}\text { Proprietário Empresa } \\
\text { / Negócio }\end{array}$ & 0 & 1,96 & 1,96 & 2,38 & 3,57 & 1,19 \\
\hline
\end{tabular}

É significativa a faixa de alunos ingressantes em situação de desemprego para os dois grupos, aproximadamente $53 \%$ para os tratados, egressos concluintes, e também aproximado $37 \%$ para o grupo de controle, os egressos evadidos. No entanto, considera-se também a significativa diferença entre a condição inicial e do momento da pesquisa para ambos os grupos. Enquanto o grupo de controle reduziu o desemprego em 16,66\%; o grupo de tratados, os egressos concluintes reduziram seu percentual em $27,46 \%$.

Em relação as situação de vínculos temporais ou de fragilidade de algumas garantias e direitos trabalhista (empregados sem carteira, contratos temporários), os dois grupos permaneceram com situações muito próximas. $\mathrm{O}$ dado inicial para o grupo de tratados é de $11,76 \%$ para $5,88 \%$, enquanto para o grupo de controle de inicial em $10,71 \%$ para $4,76 \%$.

O significativo crescimento da condição de estágio para o grupo de tratados, de $1,96 \%$ para $13,73 \%$ na condição final, se explica em razão do atendimento as regras do curso em cumprimento do período de estágio obrigatório.

Quase sem expressão os resultados que remetem as iniciativas de empreendedorismo e autonomia funcional (proprietário empresa/negócio), enquanto o grupo de tratados teve uma variação de $1.96 \%$, o grupo de controle teve de $1,19 \%$. Este resultado contribui para o debate sobre a necessidade de inclusão de disciplinas que fomentem o debate sobre estas iniciativas.

São expressivos os resultados percentuais dos dois grupos, para a condição inicial de ingresso, no que diz respeito à situação de emprego formal (empregado com carteira assinada). Somando os dois grupos, 57\% dos entrevistados/interpelados já estava, de alguma forma, inseridos no mundo do trabalho quando ingressaram no IFB, o que evidência o perfil 
do aluno-trabalhador e a possível oposta na formação profissional e tecnológica como mecanismo de futura ascensão profissional.

\subsection{ANÁLISE DOS IMPACTOS DA FORMAÇÃO, A PARTIR DAS INFORMAÇÕES DOS GRUPOS TRATADOS E GRUPO DE CONTROLE}

Ressalta-se, inicialmente, que o objeto da pesquisa, ou seja, o impacto da política a ser avaliada está sendo medido pela renda dos alunos egressos. O Gráfico 1 apresenta as rendas médias dos grupos de tratamento e controle, antes e depois do período de tratamento e suas diferenças.

Gráfico 2 - Rendas médias dos grupos de tratamento e controle (antes e depois do período de tratamento e suas diferenças)

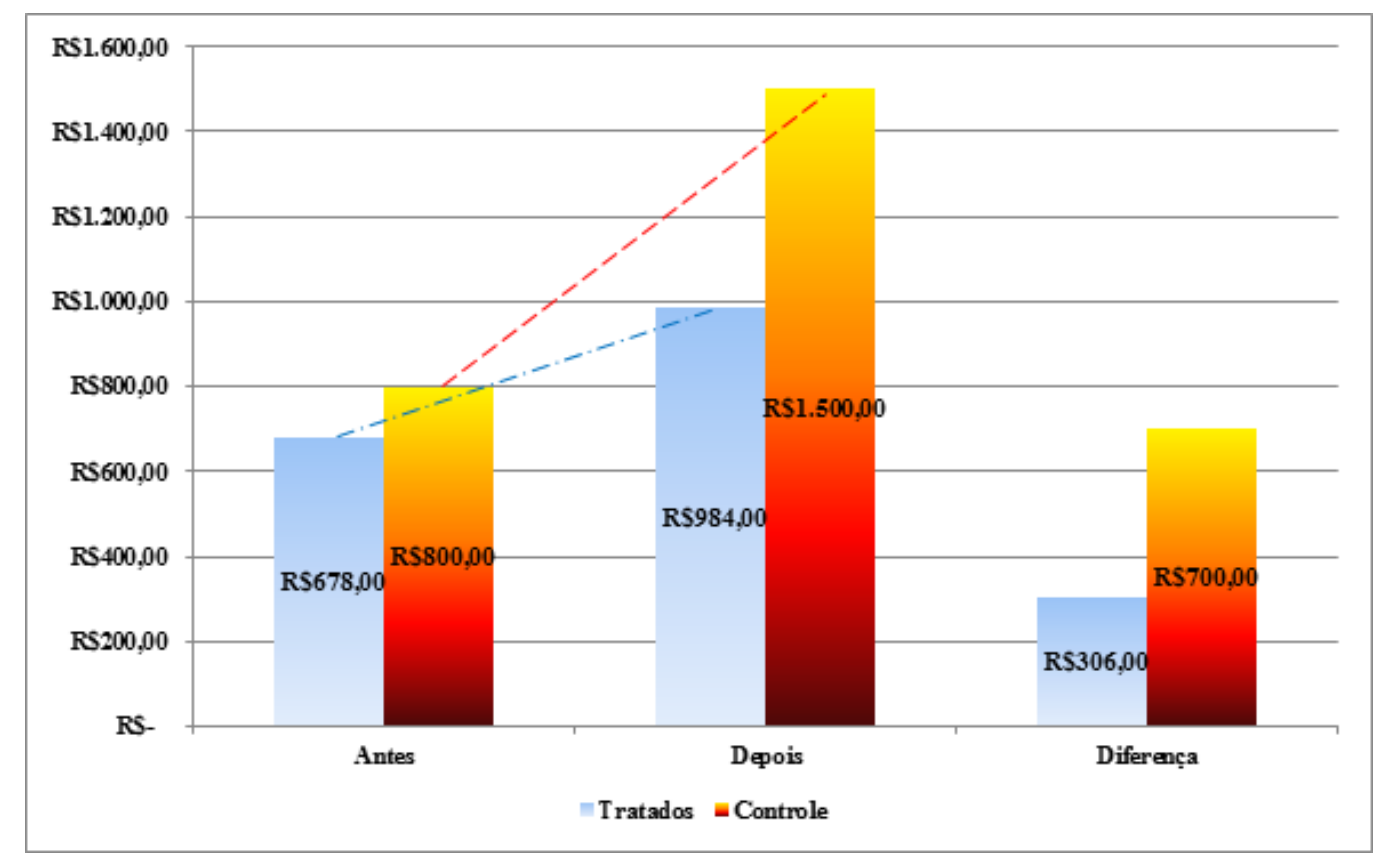

Fonte: Elaborado pelo pesquisador com base em dados da pesquisa.

Observa-se pelo que a renda média do grupo de tratamento antes de ser tratado era de $\mathrm{R} \$ 678,00$, enquanto que a renda desses mesmos indivíduos ao final do tratamento era de $\mathrm{R} \$ 984,00$, perfazendo uma diferença de $\mathrm{R} \$ 306,00$ ao final do período e um crescimento médio de $45 \%$. Da mesma maneira, o grupo de controle tinha uma renda média de $\mathrm{R} \$ 800,00$ no início do período e de $\mathrm{R} \$ 1.500,00$ ao final do período de análise, perfazendo uma diferença de $\mathrm{R} \$ 700,00$ ao final do período e um crescimento médio de $88 \%$ da renda média. 
Conforme mencionado, cabe registrar que os grupos de tratamento e controle não foram definidos por processo de aleatorização, assim, verifica-se a possibilidade de que haja diferenças entre esses grupos. Caso as diferenças estejam explicitadas pelas variáveis observadas e contidas nos modelos de regressão, esse eventual viés poderia ser controlado, caso não estejam não seria difícil de ver esse eventual viés atuando nos resultados de avaliação dessa política.

Esta limitação da pesquisa, não existiria se o grupo de controle fosse composto pelos alunos que não iniciaram os cursos, isto é, aqueles que participaram do sorteio, mas que não foram contemplados. Adotar os egressos evadidos foi a estratégia possível para esta pesquisa, mas o fato destes terem tido acesso a uma parte da formação e o conhecimento do conteúdo do curso, produz automaticamente uma autosseleção.

Seguindo a análise dos resultados dessa pesquisa, na Tabela 2 são apresentados os resultados das regressões em dados de painel, com efeito fixo, sobre o efeito de tratamento que os cursos analisados neste trabalho, ofertados pelo IFB Campus Brasília.

Tabela 2 - Análise de regressão do efeito de tratamento em concluir os cursos de Eventos, Informática e Serviços Públicos, no Campus Brasília do IFB

\begin{tabular}{|c|c|c|c|c|}
\hline \multirow{2}{*}{ Variáveis } & \multicolumn{2}{|c|}{ Renda Individual } & \multicolumn{2}{|c|}{ Renda Individual Empregado } \\
\hline & Modelo 1 & Modelo 2 & Modelo 3 & Modelo 4 \\
\hline Constante & $1.893,97 * * *$ & $-520,66$ & $1.753,672 * * *$ & $-76,39$ \\
\hline Efeito de Tratamento & $-365,33$ & $-202,36$ & $-469,47$ & $-327,74$ \\
\hline Gênero & - & $871,23 * * *$ & & $787,05 * * *$ \\
\hline Escolaridade Máxima dos Pais & - & $216,51 * * *$ & & $215,02 * * *$ \\
\hline Curso de Eventos & - & 165,47 & & 146,28 \\
\hline Curso de Informática & - & 282,38 & & 115,26 \\
\hline Número de Filhos & - & 98,16 & & $187,23 *$ \\
\hline Idade de Ingresso no IFB & - & 1,82 & & $-15,78$ \\
\hline Idade de Ingresso no IFB ao quadrado & - & 0,36 & & 0,29 \\
\hline Tempo Sabático & - & 77,84 & & 52,05 \\
\hline Tempo Sabático ao quadrado & - & 1,74 & & 2,77 \\
\hline
\end{tabular}




\begin{tabular}{|c|c|c|c|c|}
\hline Procedência Escolar - Privada & - & 127,67 & & 121,82 \\
\hline Cor Branca & - & $490,24 *$ & & 200,67 \\
\hline Turno Noturno & - & $-116,35$ & & 30,58 \\
\hline Nascimento no DF & - & 210,07 & & 175,54 \\
\hline Local Residência - Plano Piloto & - & $875,39 * * *$ & & $755,22 * * *$ \\
\hline Efeitos Temporais & Não & Sim & Não & Sim \\
\hline Número de Observações & 266 & 266 & 266 & 266 \\
\hline $\mathrm{R}^{2}$ & 0,054 & 0,288 & 0,076 & 0,326 \\
\hline Teste F (sig) & $\begin{array}{r}7,483 \\
(0,001)\end{array}$ & $\begin{array}{r}\mathbf{6 , 3 3 4} \\
(0,000)\end{array}$ & $\begin{array}{r}10,790 \\
(0,000)\end{array}$ & $\begin{array}{r}\mathbf{7 , 5 6 8} \\
(\mathbf{0 , 0 0 0})\end{array}$ \\
\hline
\end{tabular}

Fonte: Elaboração Própria do Autor.

Nota: Erro padrão entre parênteses com $\mathrm{p}<0,1=*, \mathrm{p}<0,05=* *$ e $\mathrm{p}<0,01=* * *$.

Assim, os modelos 1 e 3 são constituídos a partir do pressuposto de ocorrência de um experimento natural. Estas regressões são na verdade diferenças de médias, entre as variáveis de interesse dos grupos de tratados e de controle. Estes modelos apresentam como variável dependente a renda individual daqueles que compõem os grupos de tratamento e controle antes e depois de expostos ao efeito do tratamento.

Os outros dois modelos (2 e 4) diferem-se no sentido em que introduzem demais variáveis, abandonando a hipótese inicial de experimento natural e considerando a possibilidade de que na ausência de aleatorização para seleção dos grupos de tratamento e controle amostral, outras características afetariam os resultados do experimento. Assim, essas demais variáveis assumem o papel de variáveis de controle.

Os modelos 3 e 4 têm como variável dependente a renda individual multiplicada por uma variável dummy denominada "situação de emprego", onde é atribuído valor 1 (um) se o indivíduo declarasse estar empregado ou 0 (zero) em caso contrário. O objetivo deste artificio foi o de comparar os resultados da renda total do indivíduo, declarada por ele mesmo no instante da aplicação do questionário de pesquisa, com uma variável proxy de renda do trabalho deste indivíduo, uma vez que o efeito do tratamento deve, por hipótese, afetar sobremaneira na renda do trabalho daqueles que se submeteram ao tratamento. 
É evidente que não somente a renda do trabalho deve ser afetada, considerando que alguns indivíduos da amostra podem ser empresários, por exemplo, e aferir renda a partir do lucro de sua empresa ou participação societária. Neste caso, o tratamento poderia afetar diretamente os resultados dessa atividade e impactar na avaliação dessa política. No entanto, há casos de aquisição de renda por outros meios, por exemplo, se ele (o indivíduo) é rentista pode se presumir que o efeito do tratamento não tenha efeito direto na composição de sua renda.

Feitas estas considerações, inicia-se a análise dos principais resultados. A Tabela 2 mostra que nos quatro modelos propostos o efeito de tratamento se mostra negativo estatisticamente, não significante. $\mathrm{O}$ resultado não surpreende para quem está familiarizado com literatura (MENEZES FILHO, 2012), pois há uma expressiva produção sobre o assunto, esta mostra que quando isolamos os efeitos do tratamento com características observáveis e, sobretudo, características não observáveis, o efeito de tratamento pode ser reduzido ou mesmo nulo.

A interpretação direta desse resultado mostra que o aluno que permaneceu e obteve conclusão de seus estudos até o final do tratamento poderá ter ficado, em média, em situação pior, idêntica ou mesmo melhor que àqueles que se retiraram antes. Desta forma, o fato de não ser significantes, os resultados não apresentam uma posição de resultados conclusivos. Assim, não se pode garantir que o efeito de tratamento melhora a condição do indivíduo, no que diz respeito à renda.

Observe ainda que a variável foi estimada, em todos os modelos com valor negativo, contudo nenhum deles em um intervalo de confiança que garantisse $90 \%$ de confiabilidade.

A partir deste resultado, há necessidade de ser entendido à luz de alguns aspectos importantes, alguns já explicitados no item 3.5, Limitações encontradas para a realização da pesquisa (vide p. 43).

Em primeiro lugar, considera-se que o grupo de controle não é o ideal. No início da pesquisa, o objetivo era compor o grupo de controle com aqueles alunos que não foram comtemplados no sorteio para as vagas nos cursos. No entanto, durante o trajeto da pesquisa foi percebido que esse grupo não tinha as informações disponíveis. A alternativa para continuar o trabalho foi agrupar àqueles que abandonaram o curso, antes de seu término, como sendo o novo grupo de controle. Esta ausência do processo aleatório favorece 
diretamente o grupo que será influenciado pela autosseleção, neste caso, os egressos evadidos. Presume-se que o grupo de evadidos deva possuir características não observáveis capazes de elevar os resultados de seu rendimento no mercado de trabalho que podem, inclusive, ter sido determinantes na decisão de evasão. Alguns podem ter entendido que seu custo de oportunidade era elevado em concluir o curso e que poderiam ter melhores alternativas com a sua evasão.

Outra análise importante, que deve ser considerada, é que a avaliação de impacto pode ter significativas variações de resultados de acordo com o grau de maturidade do tratamento. Desta forma, o mesmo estudo feito em períodos distintos podem trazer resultados diferentes de acordo com a maturidade a que se chega o efeito da política pública. Registre-se que a oferta do Campus Brasília iniciou em 2009 e que ainda são precários os registros de resultados desta. A mudança, contudo, poderá acontecer nas duas direções, pois também os efeitos da política pública podem se perder com o tempo.

Um terceiro ponto a ser considerado, diz respeito à fragilidade da coleta de dados e produção informacional da composição do banco de dados desta pesquisa, quando ela se utiliza de informações recordatórias dos interpelados. Recorrer à utilização de informações declaradas pelos alunos egressos com base em fatos de dois ou três anos anteriores, pode sugerir a existências de inconsistência nas respostas.

Por último, deve-se ressaltar o problema de micronumerosidade neste trabalho. Cada um dos modelos foi rodado com apenas 135 indivíduos em dois momentos (antes e depois do tratamento). Sabe-se que amostras reduzidas podem trazer distorções sobre os verdadeiros valores dos estimadores. Ressalta-se que esta pesquisa foi à exaustão nas tentativas de aumentar o tamanho da amostra.

De qualquer maneira, em termos de resultado encontrado, não se pode afirmar se àqueles que concluíram os referidos cursos estão em situação diferente daqueles que evadiram. O que deve alertar a educadores, gestores e tomadores de decisão sobre conteúdos, estratégias educacionais e talvez a própria missão do IFB. É possível afirmar que se a diferença entre os dois grupos fosse mais ressaltada, talvez pudéssemos chegar a resultados mais conclusivos e a considerar o sinal do estimador de tratamento, o impacto poderia ser negativo.

Feitas as devidas considerações sobre o resultado de impacto, inicia-se uma análise mais precisa sobre os resultados encontrados, através dos modelos. 
O primeiro modelo, conforme descrito, considera a ocorrência de um experimento natural, ou seja, uma diferença de médias entre as variáveis de interesse dos grupos de tratados e de controle, apenas fazendo a correção monetária de todos os valores para o ano de 2015.

A utilização deste modelo pressupõe desconsiderar que os rendimentos dos indivíduos não tem qualquer relação com outros aspectos socioeconômicos. Neste modelo, assume-se a hipótese de que os indivíduos teriam formado os grupos de tratamento e controle a partir da ocorrência de um experimento natural, como citado por Wooldridge (2002), que chama a atenção para a ingenuidade contida neste argumento. Sob tal hipótese, o efeito de tratamento se mostra negativo, porém, estatisticamente não significante.

A partir do pressuposto de que outras variáveis observáveis poderiam afetar as diferenças de rendimento entre os grupos de tratamento e de controle, estas foram incorporadas aos Modelos 2 e 4. Dentre as variáveis possíveis de testagem, observa-se que apenas três das quatorze, apresentam significância estatística nos dois modelos apresentados: Gênero, Escolaridade Máxima dos Pais e Local de Residência.

No que diz respeito a variável Gênero, observa-se que os homens ganham em média $\mathrm{R} \$ 871,00$ a mais que as mulheres no Modelo 2 e cerca de $\mathrm{R} \$ 790,00$ no Modelo 4. Este resultado corrobora com resultados próximos da Pesquisa Nacional por Amostra de Domicílio (PNAD), estes apontam que as mulheres ganham em média 74,5\% do rendimento dos homens (KLEIN; GUIMARÃES, 2015). Ainda em relação aos resultados da PNAD, os maiores rendimentos médios dos pais estão no Distrito Federal, com médias de $\mathrm{R} \$ 3.528,00$ para os homens e $\mathrm{R} \$ 2.927,00$ para as mulheres, portanto uma diferença de $\mathrm{R} \$ 601,00$, bastante próxima dos resultados obtidos nesta pesquisa.

Segundo Castioni (2012), o setor público é a quinta área de ocupação no Distrito Federal, com mais da metade do PIB.

\footnotetext{
Um dos fatores deve-se à elevada dependência da estrutura econômica da cidade, que está quase que exclusivamente assentada no setor terciário, responsável por $93 \%$ do PIB local, com destaque absoluto para o setor público, compreendendo a administração pública e os serviços públicos. O setor público é responsável por mais da metade do PIB distrital, mas representa apenas um quinto da ocupação (CASTIONI, 2012, p. 100).
} 
Assim, o resultado de ambas suscita a necessidade de maiores análises, considerando uma cidade, onde os salários em grande parte são determinados por Lei e não por equilíbrio de mercado, talvez devesse apresentar um gap menor.

Outra variável que importa nos resultados é a Escolaridade Máxima dos Pais. Também nos dois modelos 2 e 4, verifica-se que indivíduos que possuem pais com maior educação tendem a ter melhores resultados no mercado de trabalho.

Para a composição desta variável no estudo, foram consideradas as informações de escolaridade individualmente do pai e da mãe declaradas pelos participantes no questionário. A partir deste peso atribuído, foi considerada para cálculo a maior escolaridade entre os dois. O peso de escolarização foi atribuído conforme quadro a seguir:

Quadro 8 - Pesos atribuídos à formação dos pais na pesquisa

\begin{tabular}{|c|c|}
\hline PESO & NÍVEL FORMAÇÃO \\
\hline 0 & Analfabeto (a) \\
\hline 1 & Ensino Fundamental \\
\hline 2 & Ensino Médio \\
\hline 3 & Ensino Técnico \\
\hline 4 & Ensino Superior \\
\hline 5 & Pós-Graduação \\
\hline
\end{tabular}

Fonte: Elaborado pelo pesquisador.

Para esta variável explicativa, o banco de dados possui a seguinte distribuição:

Tabela 3 - Distribuição da formação máxima dos pais por condição de egresso

\begin{tabular}{lcccccc}
\hline \multicolumn{1}{c}{ NIVEL FORMAÇÃO } & \multicolumn{2}{c}{$\begin{array}{c}\text { ESCOLARIZAÇÃO } \\
\text { MÁXIMA }\end{array}$} & \multicolumn{2}{c}{$\begin{array}{c}\text { EGRESSOS } \\
\text { CONCLUINTES }\end{array}$} & \multicolumn{2}{c}{$\begin{array}{c}\text { EGRESSOS } \\
\text { EVADIDOS }\end{array}$} \\
\hline Analfabeto & 10 & 7,40 & 03 & 5,88 & 07 & 8,33 \\
Ensino Fundamental & 44 & 32,60 & 19 & 37,25 & 25 & 29,76 \\
Ensino Médio & 33 & 24,45 & 10 & 19,60 & 23 & 27,38 \\
\hline
\end{tabular}




\begin{tabular}{lcccccc} 
Ensino Técnico & 08 & 5,92 & 04 & 7,85 & 04 & 4,76 \\
\hline Ensino Superior & 28 & 20,75 & 09 & 17,65 & 19 & 22,62 \\
\hline Pós-Graduação & 12 & 8,88 & 06 & 11,77 & 06 & 7,15 \\
\hline TOTAIS & $\mathbf{1 3 5}$ & $\mathbf{1 0 0 \%}$ & $\mathbf{5 1}$ & $\mathbf{1 0 0 \%}$ & $\mathbf{8 4}$ & $\mathbf{1 0 0 \%}$ \\
\hline
\end{tabular}

Segundo estudo de Silva Júnior e Sampaio (2015), o background familiar é fato determinante do sucesso escolar:

\begin{abstract}
Verifica-se, ainda, que o background familiar afeta os resultados educacionais tanto de homens quanto de mulheres somente via interação, com qualidade da escola e seus coeficientes iguais para homens e mulheres. Ainda com relação ao background familiar, quando separado por educação do pai e da mãe, interagindo com a qualidade da escola, verifica-se que os efeitos marginais são maiores para os homens em relação a esses mesmos efeitos para as mulheres. Tal resultado sugere evidências de que a educação dos pais, interagindo com a qualidade da escola, é mais importante na educação dos filhos do que na educação das filhas (s/p).
\end{abstract}

Ainda segundo o autor, filhos de pais com maior escolaridade tendem a alcançar maiores níveis de escolarização. Neste sentido, acredita-se também que tal literatura explique o resultado desta pesquisa, na relação de ganho superior da renda individual e empregabilidade, segundo o modelo 2 foi de $R \$ 216,51$, enquanto no modelo 4 foi de $R \$$ 215,02, para cada nível acima de escolaridade máxima dos pais.

Considerando ainda apenas as variáveis significantes nos dois modelos, 2 e 3, tem-se a variável Local de Residência, tendo o fato de residir no Plano Piloto, como importante característica correlacionada com os maiores rendimentos. Para efeito de cálculo desta variável, considerada como uma dummy neste estudo, foram atribuídos peso 1 para alunos residentes no Plano Piloto e regiões vizinhas e peso 0 para fora do Plano Piloto. Aqui compreendido, Plano Piloto e regiões vizinhas, as Regiões Administrativas do Plano Piloto (Asa Sul e Norte), Cruzeiro, Sudoeste, Lago Sul e Lago Norte.

No modelo 2 há um ganho de R \$ 875,39, já o modelo 4 apresenta ganho remuneratório de $\mathrm{R} \$ 755,22$ na variável renda e emprego para os alunos residentes no Plano Piloto e regiões vizinhas.

Há inúmeros estudos que evidenciam a existência e crescimento de concentração de renda em Brasília. Destaca-se o estudo do IPEA, Dimensão, Evolução e Projeção da 
Pobreza por Região e por Estado no Brasil (BRASÍLIA, 2010), este apura que enquanto a concentração de riquezas diminui nas demais unidades da Federação, o Distrito Federal apresentou um significativo aumento.

A referida pesquisa defende o argumento de que tal processo se explica, considerando que nas últimas décadas houve um forte movimento de recomposição, salarial e de pessoal, nos quadros da administração pública federal, população com forte predomínio no Plano Piloto, demais regiões administrativas e Entorno.

Segundo artigo de Bursztyn (2010), o Distrito Federal passou a ser considerado como um “oásis de prosperidade” e, portanto, com forte movimento migratório:

\begin{abstract}
Enquanto Brasília representar, no imaginário das pessoas, um oásis de prosperidade, o DF será o destino de migrantes de baixa renda, vindos de outros cantos do Brasil. Essa pressão demográfica só vai cessar no momento em que os locais de origem desses migrantes oferecerem boas oportunidades. E isso significa termos políticas de abrangência nacional, para além da simples transferência de renda: habitação, emprego, saneamento, educação e saúde (s/p).
\end{abstract}

Assim sendo, esta pesquisa vem corroborar com resultados de demais estudos, que apontam relação direta entre maior renda individual com o domicílio no Distrito Federal, em especial no Plano Piloto e demais regiões administrativas vizinhas. Resta apenas avançar na compreensão do fato, da origem da motivação destes alunos residirem na região administrativa do Plano Piloto, ou seja, se é consequência ou causa da relação com a renda, saber se o aumento de renda é o agente motivador ou não da fixação nestas regiões.

Por fim, cabe ainda destacar dois resultados significativos, no modelo 2 a relação com a variável cor e no modelo 4 a relação com a variável número de filhos.

No caso do Modelo 2, verifica-se que a variável Cor Branca apresentou resultados positivos e estatisticamente significante. É importante lembrar que essa é uma variável dummy que marca valor caso o indivíduo afirme ser de cor branca e zero em caso contrário. $\mathrm{O}$ resultado mostra que os indivíduos que declaram ser brancos recebem, em média, $\mathrm{R} \$ 490,00$ a mais que os demais indivíduos. Novamente, vários trabalhos apresentam resultados semelhantes o que sempre surpreendente, se considerarmos para um país com marcante mestiçagem como o Brasil.

No Modelo 4, verifica-se ainda que o número de filhos foi importante para maior rendimentos. Em média, cada filho a mais tende a se correlacionar com quase R\$190,00 a mais na remuneração média comparada. Este resultado apresenta certa relação, pois se 
presume que, indivíduos com maior prole têm maiores responsabilidades e se esforçam mais intensamente em seu labor, fazendo com que seus esforços elevem a produtividade média e, por consequência salários, uma vez que neste modelo a renda individual está vinculada a situação de emprego.

De maneira geral, considerando-se os dados disponíveis e aplicados a esta pesquisa, conclui-se que o efeito de tratamento não parece trazer resultados impactantes para aqueles que são tratados. A resposta dos modelos apresentados mostra que eventuais resultados impactantes de tratamento em políticas públicas semelhantes, poderá se dar pela identificação de outras características observadas e que não atuem em grupos de tratamento com viés de autosseleção. 


\section{CONSIDERAÇÕES FINAIS}

Oportuno iniciar com um registro observado e quantificado ao longo da execução da pesquisa e que embora não diretamente relacionado com o objeto, indiretamente impacta nos seus resultados.

Nesta perspectiva, foi importante analisar os elevados índices de evasão escolar dos cursos ofertados pelo Campus Brasília. Observados os dados da Tabela 1 (Relação da situação de vínculo dos egressos com o mundo do trabalho), este registro remete a $81,78 \%$ do total de matrículas do Campus, isto, considerados apenas os ingressantes dos anos de 2011 e 2012.

Quando da aplicação o levantamento das informações através da Pesquisa de Empregabilidade e Renda de Alunos Egressos do IFB (Anexo 3), considerando o significativo número de alunos egressos evadidos, foram solicitados quais as motivações para o abandono ou evasão. As opções de resposta foram retiradas da Ficha de Matrícula (Anexo 1). Foi oferecida ainda como resposta a opção: “outros”, que após serem analisadas individualmente, todas foram relacionadas às opções já existentes. Em uma análise preliminar, as respostas que dizem respeito às situações que possam ser gerenciadas pelo IFB, ou seja, as opções: "Não adaptação/interesse" e "Problemas de Infraestrutura do IFB”, representam 25\% das respostas ao questionário. O que sugere uma análise mais aprofundada destas respostas e o indicativo para futuras avaliações ou acompanhamento dos gestores.

Esta pesquisa teve como objetivo investigar através da avaliação de impacto, a inserção dos alunos egressos concluintes e evadidos dos cursos técnicos do Campus Brasília, no mundo do trabalho. Propõe ainda uma avaliação da política pública, fundamentada em instrumentos e dados estatísticos consistentes, ou seja, sem possíveis vieses de interpretação, sejam eles oriundos da política de governo, da leitura corporativa institucional ou de interpretações com o olhar pedagógico, exclusivamente.

Inicialmente a pesquisa buscou pautar-se apenas pela preocupação com a empregabilidade, ou a relação formal de vínculo com o trabalho, entendendo naquele momento esta como a razão central desta política pública. No entanto, durante a execução e ao tomar ciência da literatura existente, este conceito foi ampliado, passando a compreensão de que o eixo central da avaliação não deve ser apenas a existência dos vínculos formais de 
trabalho, mas avaliar a perspectiva de agregação desta formação para o aumento da renda destes agora ex-alunos, frente às condições como trabalhadores inseridos no mundo do trabalho.

Entender o contexto da situação de inserção dos egressos do Instituto Federal, concluintes ou não no mundo do trabalho como importantes atores, fonte de avaliação do retorno dos investimentos e esforços de formação é reconhecer nestes, forte oportunidade de ajuste de currículos e de qualificação na oferta educacional, mas também como importante estratégia de mensuração das transformações e dos anseios do mundo do trabalho, na perspectiva de um dos objetivos da Educação Profissional e Tecnológica, segundo a Resolução CNE/CP 3/2002, Art. 20 Diretrizes Curriculares Nacionais Gerais para a organização e o funcionamento dos cursos superiores de tecnologia, "Propiciar a compreensão e a avaliação dos impactos sociais, econômicos e ambientais resultantes da produção, gestão e incorporação de novas tecnologias" (BRASIL, 2002).

É necessário ter clareza da complexidade e dos inúmeros fatores que contribuem para o sucesso e garantia da inserção no Mundo do Trabalho. Entre estes podemos citar: a política econômica do país e as políticas de emprego e renda adotadas pelos Governos, apenas citando estes como os itens de maior relevância a serem analisados, desta forma compreendese que esta pesquisa contribui e não esgota a discussão e reflexão sobre o tema, tampouco implica em diminuir ou limitar a complexidade do debate.

Ao longo do desenvolvimento da pesquisa foram identificadas algumas possibilidades de informações e variáveis existentes que podem auxiliar na construção de um modelo de avaliação de impacto e de indicadores de desempenho, ainda mais robusto, como: indicadores setoriais de diversos órgãos oficiais e de organizações de classe, assim como a incorporação com outros indicadores de desempenho econômico, ou ainda, com indicadores de empregabilidade e renda de principais órgãos oficiais de estudos no setor, mas que por força do prazo de execução desta pesquisa, infelizmente não foi possível serem testados.

A pouca variedade de dados e qualidade das informações existentes, foi uma limitação para a construção do modelo. Assim, uma das primeiras indicações desta pesquisa é que o Instituto Federal de Brasília, análise e reorganize o fluxo dos processos de concorrência de vagas e ingresso de alunos, via sistema de matrículas. Tanto no que diz respeito a incorporar controles eletrônicos de dados quanto de atender e ampliar a qualidade das informações colhidas nesta fase. 
Em razão desta limitação, esta pesquisa recorreu a outro procedimento com baixa qualidade e confiabilidade, a adoção de dados recordatórios, nos questionários de coleta de dados. Cabe destacar que embora não seja esta a situação ideal, ela se mostrou como a situação possível para este exercício investigativo. É necessário construir uma série histórica para efeito de acompanhamentos e referenciamentos dos resultados.

Assim sendo, sugere-se, como melhoria de processo, a tomada de dados em quatro períodos distintos para ambos os grupos. Desta forma, com um volume maior de informações ao banco de dados, que se utiliza de informações em painel, forte característica do Modelo, estimando-se condições de qualificar, ainda mais, a avaliação. E, recomenda-se a coleta nas seguintes etapas, a saber: antes do sorteio de vagas, eliminando assim, o viés de autosseleção, no mesmo período de conclusão da oferta educativa pelo grupo de tratados, entre 18 e 24 meses após o início da oferta e em dois intervalos de anos, em médio e longo prazo após a conclusão, entre 2 a 5 anos após a conclusão da oferta educativa. Supõe-se que com estas duas últimas medições será possível validar ainda mais o "efeito reconhecimento" da formação.

Apesar das limitações que dizem respeito ao banco de dados e ausência de série histórica para comparação dos resultados, considerando as informações existentes o Método de Diferenças em Diferenças se mostrou adequado à realidade da pesquisa e o método robusto. Atesta este fato, que as variáveis explicativas identificadas e, portanto, com real significância: gênero, máxima escolaridade dos pais e local de residência no Distrito Federal refletem o mesmo posicionamento de estudos anteriores e também de alguns pressupostos empíricos.

Em relação ao principal resultado objetivado por esta pesquisa, isto é, a comparação da evolução das rendas médias entre os grupos, os resultados negativos obtidos pelo grupo de tratados ou grupo de egressos concluintes, nos quatro modelos apresentados, remete a uma interpretação inicial de que o tratamento não produziu efeitos, ou seja, a formação ofertada não garantiu aumento de renda para estes alunos.

No entanto, não é possível fazer nenhuma interpretação conclusiva destes resultados, visto que nenhum deles apresentou intervalo de confiança que garantisse $90 \%$ de confiabilidade. Fortalece, portanto, a necessidade de reforços de pesquisa. Afere-se a necessidade e preocupação com a ampliação de outras variáveis explicativas na composição do grupo amostral para as próximas pesquisas, a fim de apresentar resultados mais conclusivos. 
Além da comparação da evolução das rendas médias entre os grupos, fator central da avaliação deste estudo, também buscou-se verificar a situação de vínculos dos dois grupos de egresso no Mundo do Trabalho, como demonstrado no Capítulo 3 (Resultado Obtidos), na Tabela 1, nesta situação o grupo de egressos concluintes obteve significativa diferença na condição de redução da situação de desemprego, pois enquanto o grupo de controle, reduziu o desemprego em $16,66 \%$ o grupo de tratados reduziu seu percentual em 27,46\%. Este resultado também não pode ser apresentado como conclusivo e tampouco diretamente vinculado ao efeito do tratamento.

Assim, analisando os dados obtidos e no contexto apresentado para esta pesquisa, considerando suas limitações e necessidades de adequações já apresentadas, poderia se deduzir não conclusivamente, que embora a formação tenha garantido alguma melhora na condição de vínculo no mundo do trabalho ela não produziu melhora na condição de renda dos alunos que a concluíram.

Como toda a política pública, a Educação Profissional e Tecnológica deve buscar sempre a avaliação de seus resultados, no sentido de construção de indicadores robustos, objetivando a melhoria e adequações dos investimentos realizados.

Conclui-se que como resultado indireto, esta pesquisa suscita a discussão a respeito da adoção da avaliação de impacto desta política, tendo como referência o aluno egresso e sua condição junto ao mundo do trabalho, visto que esta é uma das principais razões do investimento público nesta área.

A maioria das avaliações existentes nesta área está focada no campo de atuação da Educação, portanto com forte ênfase e contribuições no aspecto da avaliação pedagógica. Neste sentido, acredita-se que esta pesquisa contribuirá para o fomento do debate no campo de atuação da Gestão Pública, provocando assim outras indagações e hipóteses sobre o tema, que certamente surgirão, no entanto com o olhar sobre os resultados enquanto Gestão da Política Pública. 


\section{REFERÊNCIAS BIBLIOGRÁFICAS}

ARRETCHE, Marta. Tendências no Estudo sobre Avaliação. In: RICO, Elizabeth Melo (Org.). Avaliação de Políticas Sociais: uma questão em debate. São Paulo: Cortez, 2001.

BRASIL. Lei $\mathbf{N}^{\mathbf{0}}$ 11.892, de 29 de dezembro de 2008. Institui a Rede Federal de Educação Profissional, Científica e Tecnológica, cria os Institutos Federais de Educação, Ciência e Tecnologia, e dá outras providências. Disponível em:

<http://www.planalto.gov.br/ccivil_03/_ato2007-2010/2008/lei/111892.htm>. Acesso em: 06 abr. 2015.

Ministério da Educação. Secretaria de Educação Profissional e Tecnológica.

Pesquisa Nacional de Egressos dos Cursos Técnicos da Rede Federal de Educação Profissional e Tecnológica. Brasília. 2008. Disponível em:

http://portal.mec.gov.br/index.php?option=com_docman\&view=download\&alias=6696relatoriopesquisa-redefederal\&Itemid=30192. Acesso em: 06 abr. 2015.

Ministério da Educação. Secretaria de Educação Profissional e Tecnológica. Plano

de Expansão da Rede Federal de Educação Profissional e Tecnológica. Brasília. 2007. Disponível em: http://portal.mec.gov.br/setec/arquivos/pdf/apresentacaocriteriofase2.pdf. Acesso em: 01 mar. 2016.

Resolução CNE/CP 3, de 18 de dezembro de 2002, que Instituiu as Diretrizes Curriculares Nacionais Gerais para a organização e o funcionamento dos curso superiores de tecnologia. Brasília. 2002. Disponível em < http://portal.mec.gov.br/cne/arquivos/pdf/CP032002.pdf>. Acesso em: 25 mar. 2016.

BRASÍLIA, Instituto Federal de Educação, Ciência e Tecnologia de Brasília - IFB. Plano do Curso de Educação Profissional Técnico de Nível Médio Subsequente em Eventos.

Brasília, DF: IFB, 2010.

Plano do Curso de Educação Profissional Técnico de Nível Médio

Subsequente em Informática. Brasília, DF: IFB, 2010a.

Plano do Curso de Educação Profissional Técnico de Nível Médio

Subsequente em Serviços Públicos. Brasília, DF: IFB, 2010 b.

INSTITUTO DE PESQUISA ECONÔMICA APLICADA - IPEA. Dimensão,

Evolução e Projeção da Pobreza por Região e por Estado no Brasil. Brasília (DF), 2010. Disponível em:

http://www.ipea.gov.br/agencia/images/stories/PDFs/100713_comuni58pobreza.pdf Acesso em: 25 jan. 2016. 
BUARQUE, Sérgio C. Construindo o desenvolvimento local sustentável. Rio de Janeiro: Garamond, 2002.

BURSZTYN, Marcel. Brasília, a Capital da Concentração de Renda. Brasília (DF). 2010. Disponível em: http://www.unb.br/noticias/unbagencia/artigo.php?id=288. Acesso em: 29 fev. 2016.

CAPES. COMISSÃO DE APERFEIÇOAMENTO DE PESSOAS DO NÍVEL SUPERIOR. Mestrado Profissional: O que é? Disponível em: http://www.capes.gov.br/avaliacao/sobrea-avaliacao/mestrado-profissional-o-que-e. Acesso em: 06 jan. 2016.

CASTIONI, Remi. Educação e inserção ocupacional no Distrito Federal e na Região Administrativa de Ceilândia - lócus do PROEJA-Transiarte. In: HILÁRIO, Renato (Org.). Proeja-transiarte: construindo novos sentidos para a educação de jovens e adultos trabalhadores. Brasília, DF: Verbena, 2012.

CIAVATTA, Maria. Formação profissional para o trabalho incerto: um estudo comparativo. In: FRIGOTTO, Gaudêncio (Org.). Educação e crise do trabalho: perspectivas de final de século. 9. ed. Petrópolis, RJ: Vozes, 2008.

COOPER, Ronald R.; SCHINDLER, Pamela S. Métodos de pesquisa em Administração. 7. ed. Porto Alegre, RS: Bookman, 2003.

COHEN, Ernesto; FRANCO, Rolando. Avaliação de Projetos Sociais. 8. ed. Petrópolis, RJ: Vozes, 2008.

FARIA, Carlos Aurélio Pimenta de. A política da avaliação de políticas públicas. Revista Brasileira de Ciências Sociais, São Paulo, v. 20, n. 59, p. 97-109, out. 2005.

FOGUEL, Miguel Nathan. Modelo de Resultados Potenciais. In: Avaliação Econômica de Projetos Sociais. São Paulo: Dinâmica Gráfica e Editora, 2012.

FREY, Klaus. Políticas Públicas: um debate conceitual e reflexões referentes a pratica da análise de políticas no Brasil. Planejamento e Políticas Públicas. Brasília (DF), IPEA nº 21, 2002.

FRIGOTTO, Gaudêncio; CIAVATTA, Maria. A formação do "cidadão produtivo": da política de expansão do ensino médio técnico nos anos 80 à fragmentação da Educação Profissional nos anos 90: entre discursos e imagens (2001-2004). Rio de Janeiro: UFF, 2004.

FRIGOTTO, Gaudêncio; CIAVATTA, Maria; RAMOS, Marise. O trabalho como princípio educativo no projeto de educação integral de trabalhadores. Porto Alegre, RS: Fundação para o Desenvolvimento dos Recursos Humanos, 2014. Disponível em: http://redeescoladegoverno.fdrh.rs.gov.br/upload/1392215839_O\%20TRABALHO\%20COM O\%20PRINC\%C3\%8DPIO\%20EDUCATIVO\%20NO\%20PROJETO.pdf. Acesso em: 26 mar. 2015. 
FUNDAÇÃO ITAÚ SOCIAL. Avaliação Econômica de Projetos Sociais. São Paulo: Dinâmica Gráfica e Editora, 2012. Disponível em:

<http://www.fundacaoitausocial.org.br/temas-de-atuacao/avaliacao-de-projetossociais/avaliacao-economica-de-projetos-sociais>. Acesso em: 08 dez. 2014.

GIL, Antonio Carlos. Métodos e técnicas de pesquisa social. 6. ed. São Paulo: Atlas, 2008.

GOLDEBERGER, Arthur S. A Course in Econometrics. Cambridge, Mass: Harvard University Press, 1991

GUIMARÃES, Everton Lopes. A trajetória profissional dos egressos do curso técnico em agropecuária do Instituto Federal de Educação, Ciência e Tecnologia do Norte de Minas Gerais - IFNMG - Campus Januária. 2011. Dissertação (Mestrado em Ciências) - Instituto de Agronomia. Universidade Federal Rural do Rio de Janeiro.

GUJARATI, D.N. Econometria Básica. 4 ed. São Paulo: Makron Books, 2006

KLEIN, Cristian; GUIMARÃES, Ligia. IBGE/PNAD: Mulheres recebem 74,5\% do que ganham os homens. 2015. Revista Valor Econômico. Disponível em:

http://www.valor.com.br/brasil/4315176/ibgepnad-mulheres-recebem-745-do-que-ganhamos-homens. Acesso em: 29 fev. 2016.

LASTRES, Helena M.; CASSIOLATO, José E. Glossário de Arranjos e Sistemas

Produtivos e Inovação Locais. In: Ministério do Desenvolvimento, Indústria e Comércio.

Brasília (DF), 2012. Disponível em:

http://www.mdic.gov.br//arquivos/dwnl_1289323549.pdf. Acesso em: 12 mai. 2015.

MENEZES FILHO, Naércio Aquino. Avaliação Econômica de Projetos Sociais. São Paulo: Dinâmica Gráfica e Editora, 2012.

ORGANIZAÇÃO PARA A COOPERAÇÃO E O DESENVOLVIMENTO ECONÔMICO OCDE. The OECD Glossary of Statistical Terms. Disponível em:

http://stats.oecd.org/glossary/index.htm. Acesso em: 10 abr. 2015.

RAMOS, Marília. Aspectos conceituais e metodológicos da avaliação de políticas e programas sociais. Planejamento e Políticas Públicas, n 32, jan/jul, 2009.

SANCHES, Cristina Argiles. Desenvolvimento regional a partir de clusters produtivos: o caso da agroindústria da soja no Oeste da Bahia. 2008. 183 folhas. Tese (Doutorado em Administração) - Universidade Federal da Bahia, Salvador, 2008.

SANTOS, R.L. Desenvolvimento local Sustentável: caracterização do APL de artesanato de linha do município de Tobias Barreto - SE. São Cristovão, 2007. 118 folhas. Dissertação (Mestrado em Desenvolvimento e Meio Ambiente) - Universidade Federal de Sergipe, São Cristovão, 2007. 
SILVA JÚNIOR, Luiz Honorato da; PEDROSA, Beatriz Mesquita Jardim; SILVA, Márcio Francisco. Avaliação dos Impactos do ICMS Socioambiental na Criação de Unidades de Conservação e Unidades de Tratamento de Resíduos Sólidos em Pernambuco: Uma Análise a partir do Método de Diferenças em-Diferenças. Revista de Economia do Nordeste, Fortaleza (CE), v. 44, n. 2, p. 559-574, abr-jun. 2013.

SILVA JÚNIOR, Luiz Honorato da; SAMPAIO, Yony. Qualidade da Escola e Background Familiar na Formação de Capital Humano no Brasil. Revista Planejamento e Políticas Públicas. IPEA. Brasília, n.45, jul-dez. 2015.

RAMOS, Marília. Aspectos conceituais e metodológicos da avaliação de políticas e programas sociais. Planejamento e Políticas Públicas, n 32, jan/julho, 2009.

UNICEF - FUNDO DAS NAÇÕES UNIDAS PARA A INFÂNCIA. Guide for monitoring and evaluation. New York: Unicef, 1990.

WOOLDRIDGE, Jefrey M. Econometric analysis of cross section and panel data. Massachusetts Institute of Technology, 2002. 
ANEXOS 
Anexo 1 - Ficha de Matrícula do Aluno 


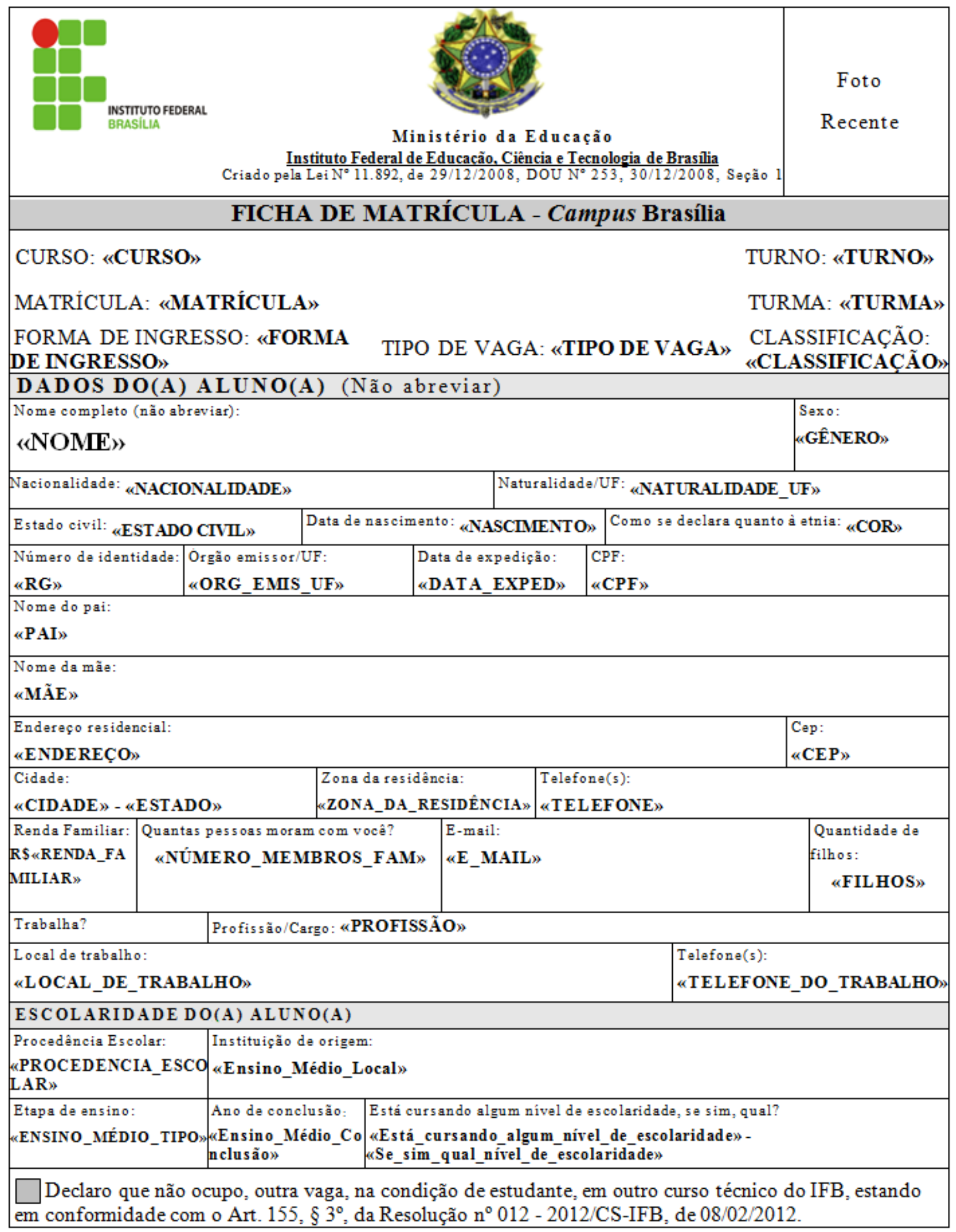


Data: «DATA_DA_MATRÍCULA»

Assinatura do Aluno(a)/Responsável

«ATENDENTE»

Registro Acadêmico

DAD OS DO(A) RESPONSA VEL (indicar pess oa para contato em caso de emergência)

Nome completo:

«NOME_DO_RESPONSÁVEL»

CPF:

«CPF_DO_RESPONSÁVEL»

Parentesco:

«PARENTESCO_COM_O_RESPONSÁVEL»

Endereço residencial:

«ENDEREC̣O_DO_RESPONSÁVEL»

\begin{tabular}{|l|l|} 
CEP: & Telefone(s): \\
«CEP_DO_RESPON & «TELEFONE_DO_RESPONSÁ \\
SÁVEL & VEL»
\end{tabular}

\begin{tabular}{l|l} 
Trabalha? & Profissão/Cargo:
\end{tabular}

«RESPONSÁVE «PROFISSÃO_DO_RESPONSÁVEL

Escolaridade:

L_TRABALHA»

«ESCOLARIDADE_DO_RESPONSÁVEL»

Local de trabalho:

«LOCAL_DE_TRABALHO_DO_RESPONSÁVEL»

INFORMAÇÖES SOBRE A SAÜDE DO(A) ALUNO(A)

Possui alguma doença? Se sim, qual?
«Possui_alguma_doença_»: «Se_sim_qual_doença»

Necessita de algum atendimento especializado? Se sim, qual?

«Necessita_de_algum_atendimento_especializado»:

«Se_sim_qual_atendimento_especializado»

Possui alguma deficiência? Se sim, qual? CID «PCD»: *QUAL_DEFICIENCIA»: «CID_PCD*

Toma alguma medicação de uso contínuo? Se sim, qual?

"Toma_alguma_medicação_de_uso_contínuo_":

«Se_sim_qual_medicação»

DOCUMENTOS ENTREGUES NO ATO DA MATRICULA

«DOCUMENTAÇAO_ENTREGUE*

DOCUMENTACQÁO PENDENTE

«DOCUMENTAÇAO_PENDENTE»

Emissão de declaração de pas se estudantil?

«Emitir_declaração_de_escolaridade_passe»

\begin{tabular}{|l|l|l|l|}
\hline \multicolumn{3}{|l|}{ SISTEMAS: } \\
\hline$\square$ SISTEC & $\square$ DIARIO DRIVE & $\square$ SISTEMA ACADËMICO & $\square$ SEGURO DE VIDA \\
\hline
\end{tabular}

CANCELAMENTO DA MATRÍCULA

MOTIVO (OPTATIVO) 
Estou ciente que, ao solicitar cancelamento de curso, serei considerado comodesistente davaga que ocupo e somente poderei retornar ao curso por meio de novo processo seletivo.

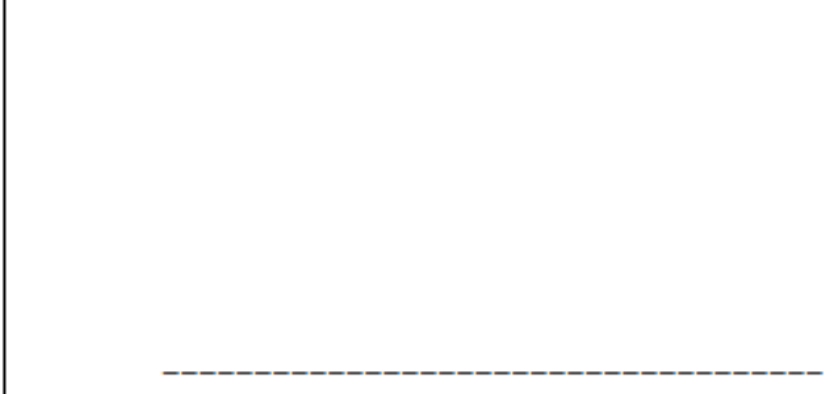

Assinatura do aluno

Data:

\section{Assinatura do aluno}

( ) Familia

( ) Distância

( ) Outrocurso

( ) Horário

( ) Trabalho

( ) Não adaptação

( ) Outro: 
Anexo 2 - Pesquisa de empregabilidade e renda de alunos egressos do IFB encaminhada a estes pelo pesquisador

\section{PESQUISA DE EMPREGABILIDADE E RENDA DE ALUNOS EGRESSOS DO IFB}

Prezado(a) Ex-aluno(a) do Instituto Federal de Brasília - IFB,

Sou Prof. Elias Oliveira do Campus Brasília e estou desenvolvendo uma pesquisa acadêmica para minha pós-graduação cujo objetivo é avaliar o impacto da inserção de ex-alunos(as) do IFB no mercado de trabalho.

Como você foi um(a) aluno(a), ainda que não tenha concluído, que ingressou entre os períodos de 2011 e 2012 em um dos nossos CURSOS TÉCNICOS em nosso Campus Brasília estou encaminhando o presente questionário.

Para validar este estudo, necessito de sua valorosa contribuição respondendo à pesquisa, composta de questões de múltipla escolha. Você não levará mais do que 05 minutos de seu tempo.

Seu nome e dados não serão citados individualmente no trabalho garantindo assim sua privacidade pessoal e profissional.

Os resultados dessa pesquisa serão entregues à Direção do Campus para análise e contribuições de melhorias aos cursos.

Conto com seu valoroso apoio.

Obrigado!

Clique Aqui: Questionário de Pesquisa

Elias Vieira de Oliveira

Docente de Área de Gestão e Negócio - Instituto Federal de Brasília

Mestrando Gestão Pública - Universidade de Brasília - Faculdade de Planaltina 


\section{Anexo 3 - Questionário}

\section{PESQUISA DE EMPREGABILIDADE E RENDA DE ALUNOS EGRESSOS DO IFB}

Prezado(a) Ex-aluno(a) do Instituto Federal de Brasília - IFB,

Sou Prof. Elias Oliveira do Campus Brasília e estou desenvolvendo uma pesquisa acadêmica para minha pós-graduação cujo objetivo é avaliar o impacto da inserção de ex-alunos(as) do IFB no mercado de trabalho.

Como você foi um(a) aluno(a) que ingressou entre os anos de 2011 e 2012, em um dos CURSOS TÉCNICOS do Campus Brasília, estou encaminhando o presente questionário.

Para validar este estudo, necessito de sua valorosa contribuição respondendo à pesquisa, composta de questões de múltipla escolha. Você não levará mais do que 05 (cinco) minutos de seu tempo.

Seu nome e dados não serão citados individualmente no trabalho garantindo assim sua privacidade pessoal e profissional.

Os resultados dessa pesquisa serão entregues à Direção do Campus para análise e contribuições de melhorias aos cursos.

Conto com seu valoroso apoio.

Obrigado!

*Obrigatório

Por gentileza, confirme seu e-mail digitando na caixa abaixo. *

Esta pergunta é obrigatória

Atualmente, quantas pessoas residem com você?

\section{Qual a escolaridade de sua mãe?}

Analfabeta 


\section{Ensino Fundamental \\ Ensino Médio \\ Ensino Técnico \\ Ensino Superior \\ Pós Graduação}

\section{Qual a escolaridade de seu pai?}
Analfabeto
Ensino Fundamental
Ensino Médio
C Ensino Técnico
E Ensino Superior
Pós Graduação

Caso você tenha filhos, informe quantos.

Em relação à minha formação profissional, ANTES de ingressar no IFB, eu:
Não havia participado de cursos de formação profissional
Havia participado de outros cursos de formação profissional, de curta duração
Havia participado de outro curso técnico, sem concluí-lo
Havia cursado o Ensino Superior sem conclusão
Havia concluído o Ensino Superior

Na ocasião em que INICIEI meus estudos no IFB, em relação à minha situação de trabalho, eu:
Estava desempregado(a)
Estava empregado(a) sem carteira assinada
Estava empregado(a) com carteira assinada 
Estava em contrato temporário

Era servidor(a) / funcionário(a) público(a)

Era autônomo(a) / prestador(a) de serviço

Era estagiário(a)

Era proprietário(a) de empresa / negócio

Qual era sua renda aproximada quando INICIOU seus estudos no IFB?

Qual a sua situação de trabalho, ATUAL?

Estou desempregado(a)

Estou empregado(a) sem carteira assinada

Estou empregado(a) com carteira assinada

Estou em contrato temporário

Sou servidor(a) / funcionário(a) público(a)

Sou autônomo(a) / prestador(a) de serviço

Sou estagiário(a)

Sou proprietário(a) de empresa / negócio

(C) Outro:

Em relação a minha formação profissional, APÓS o curso técnico do IFB, eu:

Não participei de outros cursos de formação

Participei de outros cursos de formação/capacitação

Participei de outro curso técnico sem concluí-lo

Participei e concluí outro curso técnico

Cursei / Estou cursando o Ensino Superior sem conclusão

C Cursei e concluí o Ensino Superior 
Qual a renda FAMILIAR ATUAL? (Soma das rendas de todos integrantes da família que residem com você)

\section{Qual sua renda atual?}

Na sua opinião, considerando sua formação atual, sua remuneração está:
Abaixo da média do mercado
Na média do mercado
Acima da média do mercado
Não sei / não posso opinar

Em relação à sua área de formação do curso técnico que você participou, atualmente, eu:

Não tenho interesse de trabalhar na área

Não tenho interesse de trabalhar nesta área e estou completando estudos em outra área completa

Tenho interesse de trabalhar na área, mas não atuo no momento

Estou trabalhando na área

Atualmente estou trabalhando e aprimorando os estudos nesta área

De modo geral, como avalia o curso técnico do qual participou?
Ótimo
B Bom
Regular
Ruim
6 Péssimo
Não Opinar 
Qual o principal motivo da não conclusão do curso?

Eu concluí o curso

Motivos familiares

Distância e dificuldade de deslocamento

Mudança para outro curso

D Dificuldades de conciliar horários

Trabalho

C Não adaptação / interesse

Problemas de infraestrutura do IFB

(C) Outro:

O espaço abaixo é destinado para suas considerações, comentários ou sugestões a respeito desta pesquisa ou do curso realizado no IFB. 